\title{
A Survey of Enhanced Cold Tolerance and Low-Temperature-Induced Anthocyanin Accumulation in a Novel Zoysia japonica Biotype
}

\author{
Hai-Xiang Jin ${ }^{1,2,+}$, Ming Jiang ${ }^{1,3,+}$, Jian-Feng Yang ${ }^{2}$, Zhi-Hao Wu ${ }^{1,3}$, Long-Long Ma ${ }^{1,3}$, Cong-Cong Wang ${ }^{1,3}$, \\ Chen Liang ${ }^{1,2,3}$, Xin-Yi Ning ${ }^{1,3,4}$, Liang-Fa Ge ${ }^{3, *}$ and Shu Chen ${ }^{1, *}$
}

check for

updates

Citation: Jin, H.-X.; Jiang, M.; Yang, J.-F.; Wu, Z.-H.; Ma, L.-L.; Wang, C.-C.; Liang, C.; Ning, X.-Y.; Ge, L.-F.; Chen, S. A Survey of Enhanced Cold Tolerance and Low-Temperature-

Induced Anthocyanin Accumulation in a Novel Zoysia japonica Biotype. Plants 2022, 11, 429. https:// doi.org/10.3390/plants11030429

Academic Editor: Yong-Gu Cho

Received: 29 December 2021

Accepted: 1 February 2022

Published: 4 February 2022

Publisher's Note: MDPI stays neutral with regard to jurisdictional claims in published maps and institutional affiliations.

Copyright: (C) 2022 by the authors. Licensee MDPI, Basel, Switzerland. This article is an open access article distributed under the terms and conditions of the Creative Commons Attribution (CC BY) license (https:// creativecommons.org/licenses/by/ $4.0 /)$.
1 Department of Grassland Science, College of Forestry and Landscape Architecture, South China Agricultural University, Guangzhou 510642, China; jinhaixianggzlc@hotmail.com (H.-X.J.); mingjiang@stu.scau.edu.cn (M.J.); zhhaowu@stu.scau.edu.cn (Z.-H.W.); malonglong@stu.scau.edu.cn (L.-L.M.); congcongwang@stu.scau.edu.cn (C.-C.W.); 201713010112@stu.scau.edu.cn (C.L.); nxyiii@stu.njau.edu.cn (X.-Y.N.)

2 Guangzhou Landscaping Company, Guangzhou 510440, China; yangyjf@139.com

3 Guangdong Engineering Research Center for Grassland Science, Guangzhou 510642, China

4 Department of Ornamental Horticulture, College of Horticulture, Nanjing Agriculture University, Nanjing 210095, China

* Correspondence: lge@scau.edu.cn (L.-F.G.); shuchen@scau.edu.cn (S.C.)

+ These authors contributed equally to this work.

\begin{abstract}
Zoysia japonica is a warm-season turfgrass that is extensively used in landscaping, sports fields, and golf courses worldwide. Uncovering the low-temperature response mechanism of Z. japonica can help to accelerate the development of new cold-tolerant cultivars, which could be used to prolong the ornamental and usage duration of turf. A novel Z. japonica biotype, YueNong-9 (YN-9), was collected from northeastern China for this study. Phenotypic measurements, cold-tolerance investigation, and whole-transcriptome surveys were performed on YN-9 and Lan Yin-3 (LY-3), the most popular Z. japonica cultivar in Southern China. The results indicated the following: YN-9 has longer second and third leaves than LY-3; when exposed to the natural low temperature during winter in Guangzhou, YN-9 accumulated 4.74 times more anthocyanin than LY-3; after cold acclimation and freezing treatment, $83.25 \pm 9.55 \%$ of YN-9 survived while all LY-3 leaves died, and the dark green color index (DGCI) value of YN-9 was 1.78 times that of LY-3; in YN-9, there was a unique up-regulation of Phenylalanine ammonia-lyase (PAL), Homeobox-leucine Zipper IV (HD-ZIP), and $A T P$-Binding Cassette transporter B8 (ABCB8) expressions, as well as a unique down-regulation of zinc-regulated transporters and iron-regulated transporter-like proteins (ZIPs) expression, which may promote anthocyanin biosynthesis, transport, and accumulation. In conclusion, YN-9 exhibited enhanced cold tolerance and is thus an excellent candidate for breeding cold-tolerant Z. japonica variety, and its unique low-temperature-induced anthocyanin accumulation and gene responses provide ideas and candidate genes for the study of low-temperature tolerance mechanisms and genetic engineering breeding.
\end{abstract}

Keywords: turfgrass; abiotic stress; anthocyanin biosynthesis; anthocyanin transport; RNA-seq

\section{Introduction}

Zoysiagrasses are species of the genus Zoysia Willd. that are native throughout the western Pacific Rim and the Indian Ocean [1,2]. Although this genus contains 11 species, only 3 of them, Z. japonica Steud., Z. matrella (L.) Merr., and Z. pacifica (Goudswaard) Hotta and Kuroki, previously known as Z. tenuifolia, and their interspecific hybrids, have been widely used for various turfgrass applications, including home lawns, golf course tees, fairways and greens, road sides and medians, and other recreational sites [3-5]. These zoysiagrass varieties have acquired favor among turfgrass practitioners due to their 
minimal cultural demands, water-use efficiency, and extensive tolerance to cold, shade, salt, diseases, and insects $[5,6]$.

Research progress in zoysiagrass have been relatively slow when compared to major agricultural crops, mostly because Zoysia is a perennial, open-pollinated, polyploid grass, making it genetically complicated and a challenging candidate to study. Other factors, such as insufficient funding for genomic research, limited prior omic information, major traits controlled by a small number of genes (QTL, quantitative trait loci), and a lack of information on reproducible phenotyping systems, have added extra obstacles and slowed advances in zoysiagrass research [6].

Whole transcriptome analysis based on next-generation sequencing technologies has developed as a useful approach for finding and identifying genes involved in abiotic stress resistance in recent years, drastically enhancing our understanding of the interaction between plant and environment. To date, the NCBI database holds 11 transcriptomic BioProjects for Zoysia species, including 8 for Z. japonica, 2 for Z. matrella [7,8], and 1 for $Z$. macrostachya [9]. Among the eight transcriptomic studies on Z. japonica, two focused on spike pigmentation [10], one on responses to pathogen invasion [11], and the others on responses to abiotic stresses, including aluminum, wounding [12], salt $[13,14]$ and low-temperature [15].

Low temperature is a serious abiotic stress that produces reactive oxygen species (ROS), causing oxidative damage to cellular activities and endangering plant development and agricultural production. To adapt to low-temperature stress, plants have evolved intricate defensive mechanisms at the molecular, physiological, and biochemical levels [16-19], including the activation of the cellular antioxidant machinery for the purpose of scavenging ROS. Anthocyanins may scavenge ROS as an efficient antioxidant by neutralizing radicals with their hydroxyl groups to preserve normal cellular redox homeostasis; hence, plants often generate anthocyanins to reduce oxidative damage caused by low-temperature stress [20-25]. Low-temperature responsive networks in zoysiagrass have been investigated through physiological, biochemical, molecular, genetic and omic approaches $[7,15,26-37]$. However, no studies have attempted to associate anthocyanin accumulation with cold tolerance in zoysiagrass.

In this study, we reported a Z. japonica biotype collected from Lvshun West Station in northeast China and named as YueNong No. 9 (YN-9) (Figure S1), and compared its cold responses and tolerance against the most extensively used Z. japonica cultivar in south China, LanYin No. 3 (LY-3). The results indicated that YN-9 had better cold tolerance, accumulated anthocyanin more efficiently, and displayed unique variations of gene expressions favoring anthocyanin biosynthesis, transport, and accumulation at a lower temperature than LY-3. This study provided a novel zoysiagrass biotype with great potential for development into a cold-tolerant variety that could be used for various turf applications to extend the green period during autumn and winter, as well as candidate genes for genetic engineering breeding of zoysiagrass with enhanced cold tolerance and anthocyanin accumulation, which should advance genetic and molecular research on turfgrass and ameliorate the existing condition of a shortage of turfgrass cultivars in China.

\section{Results}

\subsection{YN-9 Is a Zoysia japonica Biotype}

YN-9 is a perennial grass growing with both rhizomes and stolons with the following phenotypic characteristics: the second leaves $12.47 \pm 2.28 \mathrm{~cm}$ long and $3.92 \pm 0.41 \mathrm{~mm}$ wide; the third leaves $14.75 \pm 2.59 \mathrm{~cm}$ long and $3.93 \pm 0.48 \mathrm{~mm}$ wide; inflorescences $38.20 \pm 3.77 \mathrm{~mm}$ long and $1.92 \pm 0.17 \mathrm{~mm}$ wide; spikelets $3.39 \pm 0.47 \mathrm{~mm}$ long and $1.24 \pm 0.16 \mathrm{~mm}$ wide; and pedicels $4.25 \pm 1.36 \mathrm{~mm}$ long and usually longer than the spikelete attached (Figure 1). According to previous taxonomic publications [1,2,5], YN-9 was identified as Zoysia japonica. The leaf blade is the organ that most directly affects turfgrass's aesthetic and athletic performance. Leaf width determines the texture of the turf, while leaf length determines the mowing height. Thus, the leaf length and width of 
YN-9 were compared to those of LY-3, the most extensively utilized Z. japonica cultivar for urban greening and sports fields in Southern China. The results indicated that the second and third leaf blades of YN-9 were $22.37 \%$ and $23.63 \%$ longer than that of LY-3, respectively, but no significant differences in leaf widths were observed (Table 1).

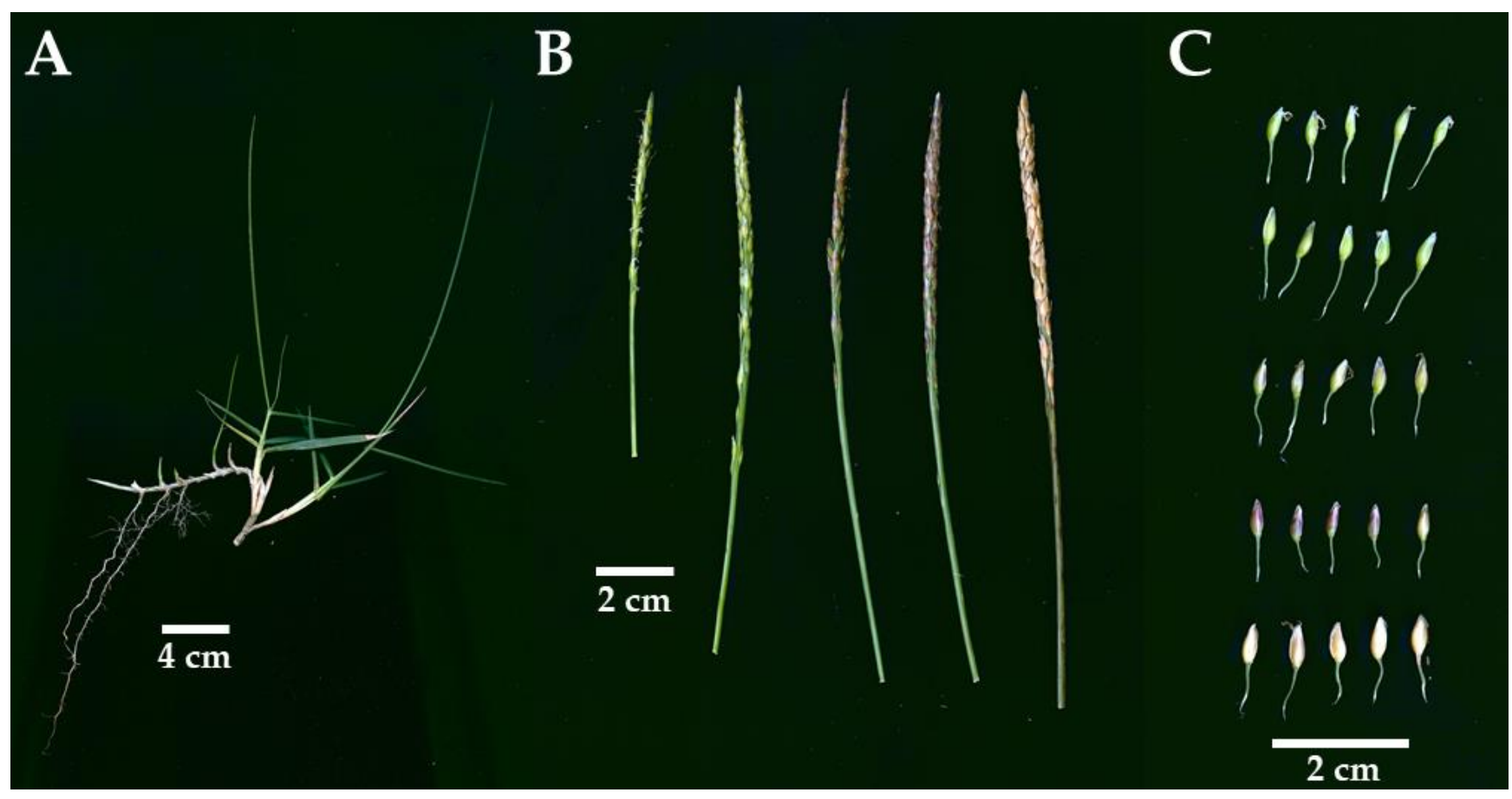

Figure 1. Phenotypic characteristics of YN-9 Zoysia japonica: (A) shoot and rhizome; (B) inflorescence and seedhead; (C) spikelete with pedicel.

Table 1. Comparison of leaf blade length and width between YN-9 and LY-3.

\begin{tabular}{ccccc}
\hline \multirow{2}{*}{ Genotype } & \multicolumn{2}{c}{ 2nd Leaf } & \multicolumn{2}{c}{ 3rd Leaf } \\
\cline { 2 - 5 } & Length $\mathbf{( c m )}$ & Width $\mathbf{( m m )}$ & Length $\mathbf{( c m )}$ & Width $(\mathbf{m m})$ \\
\hline LY-3 & $10.19 \pm 1.78$ & $4.02 \pm 0.55$ & $11.93 \pm 2.59$ & $4.05 \pm 0.58$ \\
YN-9 & $12.47 \pm 2.28^{* *}$ & $3.92 \pm 0.41$ & $14.75 \pm 2.59 * *$ & $3.93 \pm 0.48$ \\
\hline
\end{tabular}

Note: ${ }^{* *}$ indicates a significant difference $(p$-value $<0.01)$ between LY-3 and YN-9.

\subsection{Enhanced Anthocyanin Accumulation and Cold Tolerance in YN-9}

When LY-3 and YN-9 were grown in the natural low temperature of winter in Guangzhou (Table S1), YN-9 produced significantly more red to reddish-purple leaf blades than LY-3 (Figure 2a). Anthocyanin is measured because it is the primary source of red and purple pigmentation in plant tissues. The results showed that the anthocyanin content of YN-9 leaves after winter increased to 5.74 times that of before winter, and was significantly higher than that of LY-3 (Figure 2b), which is consistent with their leaf color variation after winter.

YN-9 was collected in Lvshun West Station in Dalian, China $\left(121^{\circ} 7^{\prime} 48^{\prime \prime} \mathrm{E}, 38^{\circ} 49^{\prime} 12^{\prime \prime} \mathrm{N}\right)$. LY-3 was chosen as the control group to compare with YN-9 for cold tolerance assessment. All leaves of LY-3 perished after cold acclimation and freezing treatment, but only 5-30\% YN-9 showed symptoms of yellowing and withering (Figure 3a). The DGCI value of LY-3 dropped from $70 \%$ to $45 \%$ after cold treatment, while the DGCI value of YN-9 increased from $67 \%$ to $80 \%$, which was 1.78 times that of LY-3 (Figure $3 \mathrm{~b}$ ). All these results implied that YN-9 was significantly more cold-tolerant than LY-3. 


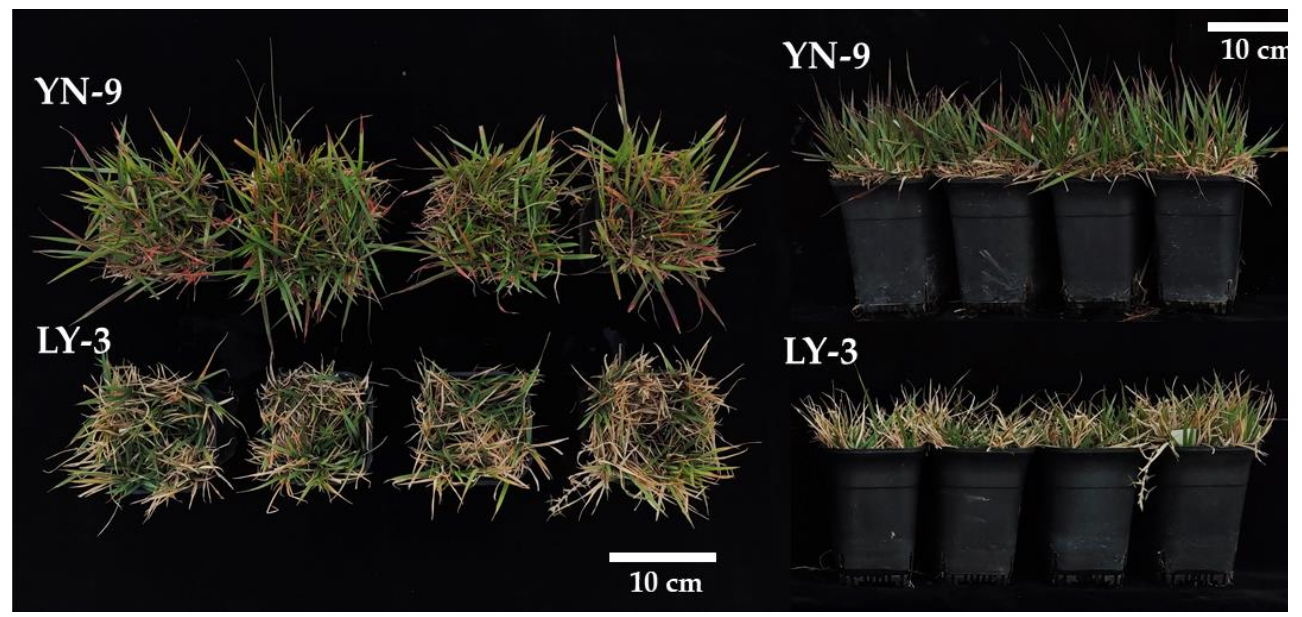

(a)

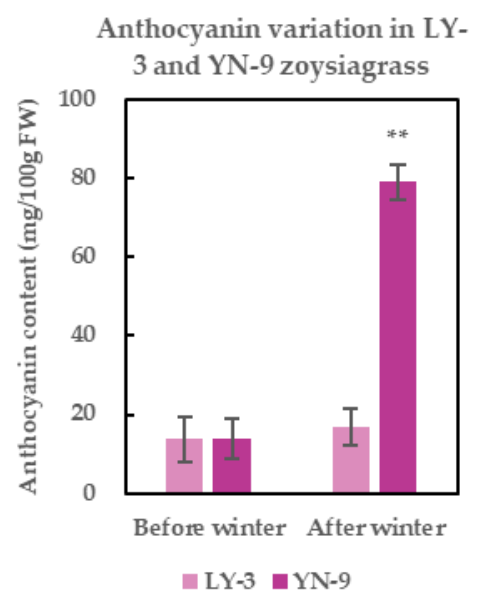

(b)

Figure 2. Leaf color and anthocyanin content variations in LY-3 and YN-9 after winter in Guangzhou. (a) Photos of LY-3 and YN-9 after winter in Guangzhou; (b) Anthocyanin content of LY-3 and YN-9 leaves before and after winter in Guangzhou; ${ }^{* *}$ above the error bar indicates a significant difference ( $p$-value $<0.01$ ) between LY-3 and YN-9.
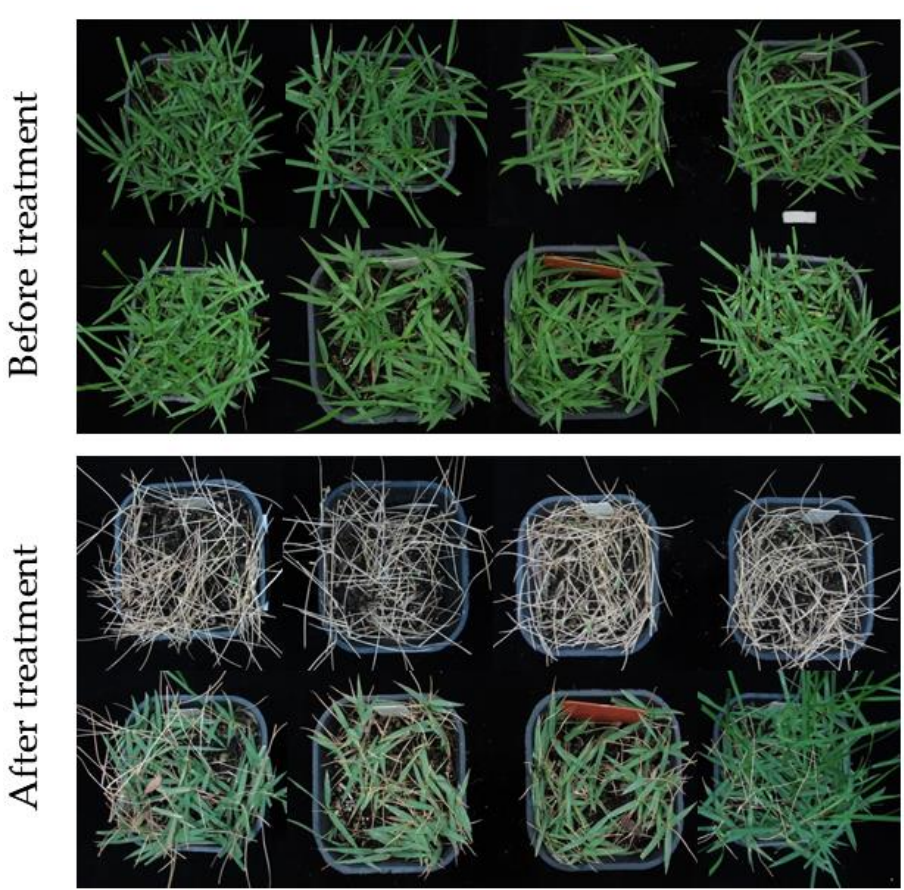

(a)
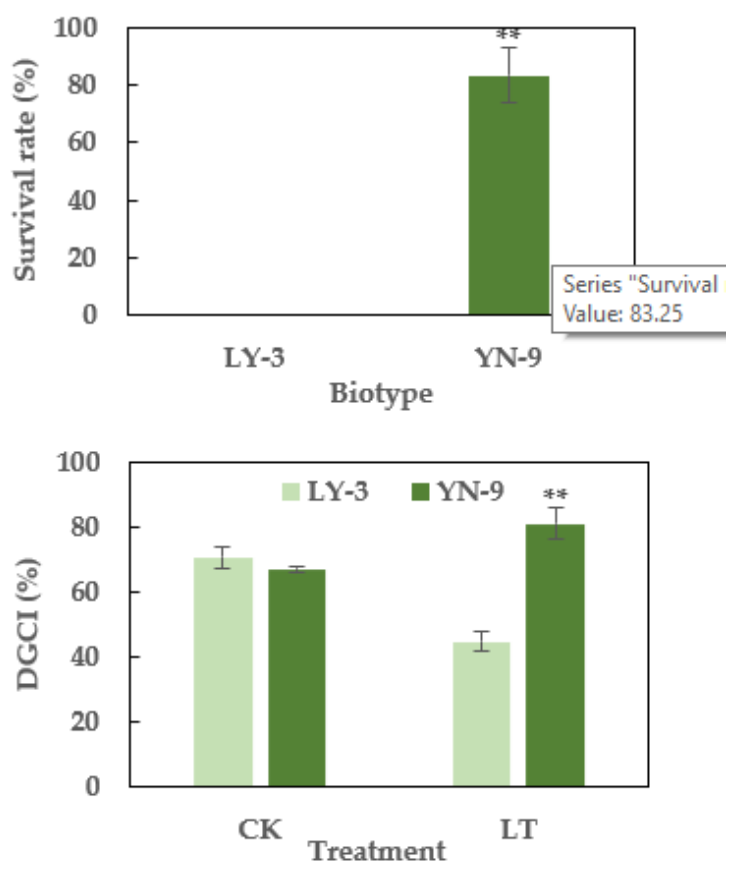

(b)

Figure 3. Phenotypic variations and survival rates of LY-3 and YN-009 after low-temperature treatment. (a) Photos of LY-3 and YN-9 before and after low-temperature treatment; (b) Survival rates and DGCI variations of LY-3 and YN-9 after low-temperature treatment; DGCI represents for dark green color index, ${ }^{* *}$ indicates a significant difference $(p$-value $<0.01)$ between LY-3 and YN-9, CK indicates DGCI values before treatment, LT indicates DGCI values after treatment.

\subsection{Read Trimming and Mapping}

A total of 18 cDNA libraries were synthesized from RNA samples of two zoysiagrass biotypes (YN-9 and LY-3) collected at different treatment times (before treatment, after cold acclimation, and after freezing treatment) with three biological replicates, and then 
sequenced using the HiSeq X-ten. A total of 841,324,594 high-quality paired-end clean reads with read length of $150 \mathrm{bp}, \mathrm{Q} 20$ (the proportion of nucleotides with a quality score $\geq 20$ in all nucleotides) of $95.03 \%$, and GC content of $51.58 \%$ were yielded after filtering and trimming. Using Hisat2, the clean reads were mapped to the Z. japonica reference genome with an average mapping rate of $87.14 \%$ (Table S2).

\subsection{DEGs after Cold Treatment}

After cold acclimation (at $4{ }^{\circ} \mathrm{C}$ for 3 days), 9278 and 10196 genes were up-regulated in LY-3 and YN-9 leaves, respectively; 7046 and 7512 genes were down-regulated in LY-3 and YN-9 leaves, respectively. Among these genes, 7044 up-regulated and 4953 down-regulated genes were shared by the two Zoysia biotypes, whereas 3152 up-regulated and 2559 downregulated genes were unique to YN-9 (Figure 4). After freezing treatment (at $-4{ }^{\circ} \mathrm{C}$ for 1 day), 9244 and 10058 genes were up-regulated in LY-3 and YN-9 leaves, respectively; 8818 and 8396 genes were down-regulated in LY-3 and YN-9 leaves, respectively. Among these genes, 6883 up-regulated and 5933 down-regulated genes were shared by the two Zoysia biotypes, whereas 3175 up-regulated and 2885 down-regulated genes were unique to YN-9 (Figure 4).

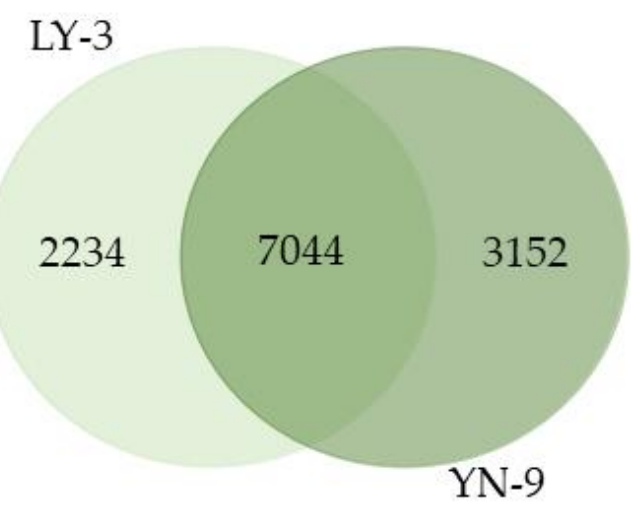

LY-3

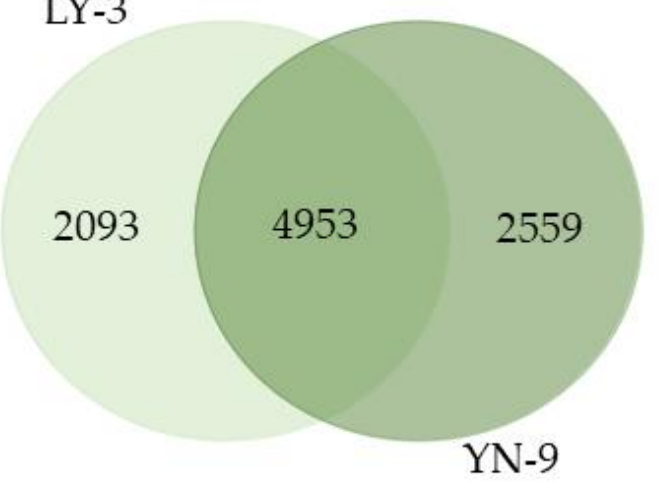

CA
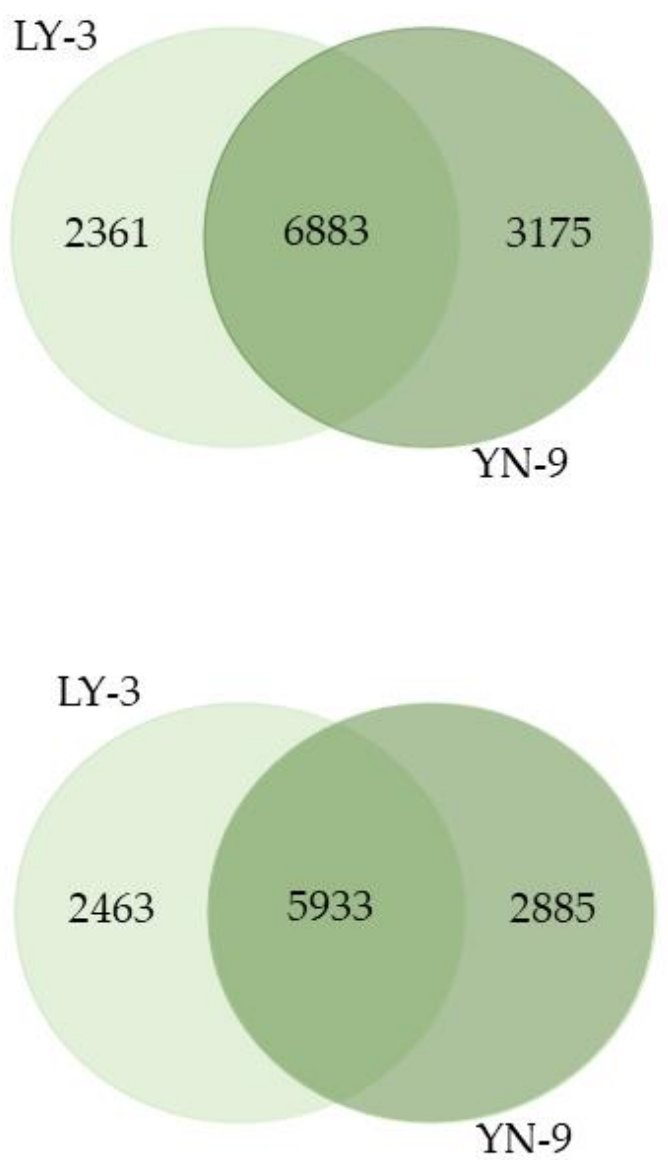

FZ

Figure 4. Venn diagram of up-regulated $\left(\log _{2} \mathrm{FC}>1\right.$ and $p$-value adjusted $\left.<0.05\right)$ and down-regulated genes $\left(\log _{2} \mathrm{FC}<-1\right.$ and $p$-value adjusted $\left.<0.05\right)$ of LY-3 and YN-9 after cold acclimation $(\mathrm{CA})$ and freezing (FZ) treatment.

YN-9 had more differentially expressed genes than LY-3 following cold acclimation or freezing treatment, particularly those that were up-regulated (Figure 4). The distribution of up-regulated genes in different $\log _{2}$ Fold Change $\left(\log _{2} \mathrm{FC}\right)$ intervals revealed that when 
$\log _{2} \mathrm{FC}$ was between 3 and 6, the difference in the number of up-regulated genes between the two biotypes expanded (Figure 5). As a result, DEGs for downstream GO and KEGG enrichment analyses were selected based on multiple $\log _{2} \mathrm{FC}$ thresholds instead of one single $\log _{2} \mathrm{FC}$ threshold.

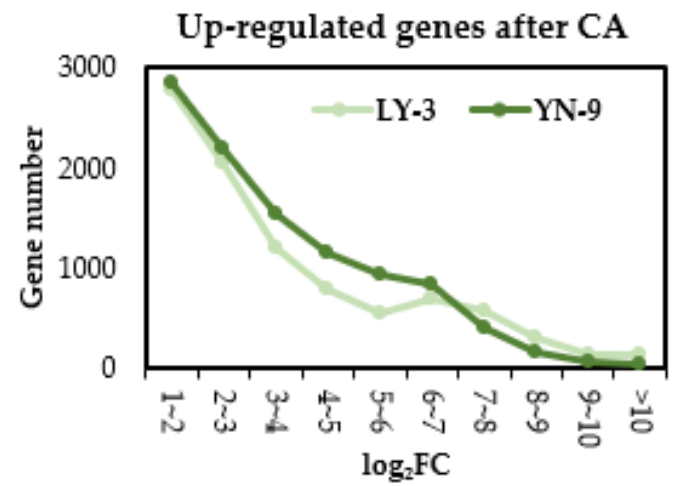

Down-regulated genes after CA

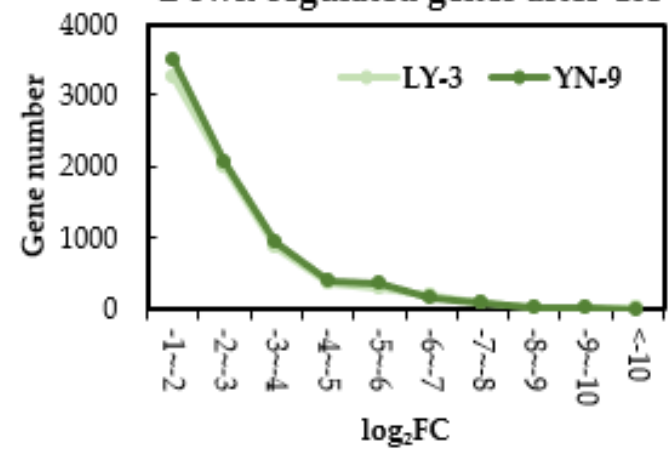

Up-reulated genes after FZ

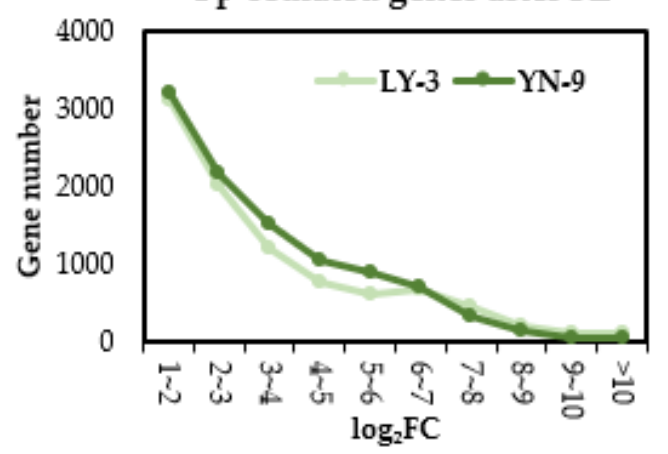

Down-regulated genes after FZ

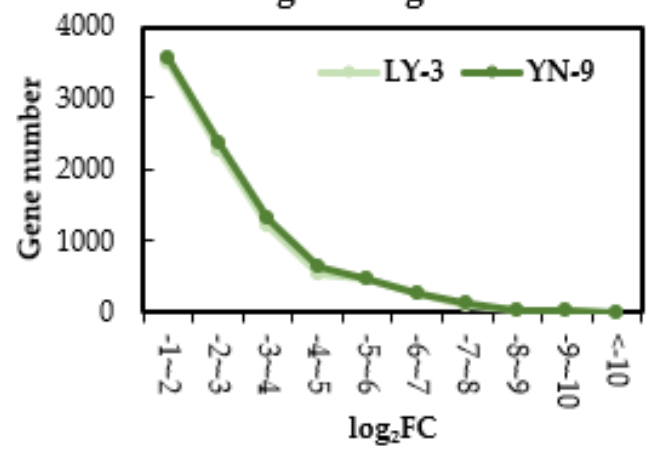

Figure 5. Distribution of up-regulated $\left(\log _{2} \mathrm{FC}>1\right.$ and $p$-value adjusted $\left.<0.05\right)$ and down-regulated genes $\left(\log _{2} \mathrm{FC}<-1\right.$ and $p$-value adjusted $\left.<0.05\right)$ of LY-3 and YN-9 after cold acclimation $(\mathrm{CA})$ and freezing (FZ) treatment in different $\log _{2} \mathrm{FC}$ intervals.

\subsection{Genes Enriched in Pigmentation GOs}

2.5.1. HD-Zop IV

When the screening criteria for up-regulated genes were elevated to $\log _{2} \mathrm{FC}>2$ and $p$-value adjusted $<0.05$, genes that were uniquely up-regulated in YN-9-following cold acclimation were enriched in four Biological Process GO categories associated with pigment accumulation, which were GO:0043478, GO:0043479, GO:0043480 and GO:0043481. These entries all comprise seven genes, three of which belong to the ABC Transporter $B(A B C B)$ family and four of which belong to the Homeobox-leucine Zipper IV (HD-ZIP IV) subfamily (Figure 6).

The four pigmentation-related HD-ZIP IV genes encode protein sequences with typical HD-ZIP IV structural features, HD-ZIP-START-SAD (Figure 6), and these protein sequences showed very high similarity with Arabidopsis ANL2 (AT4G00730.1) and HDG1 (AT3G61150.1) according to their BLAST results against TAIR protein database and multiple sequence alignment with Arabidopsis HD-ZIP IV members (Figure S2 and Table S3). Phylogenetic analysis of these four proteins with 16 Arabidopsis HD-ZIP IV members also clustered them together with ANL2 and HDG1, supported by a bootstrap value of $99 \%$ (Figure 7). 


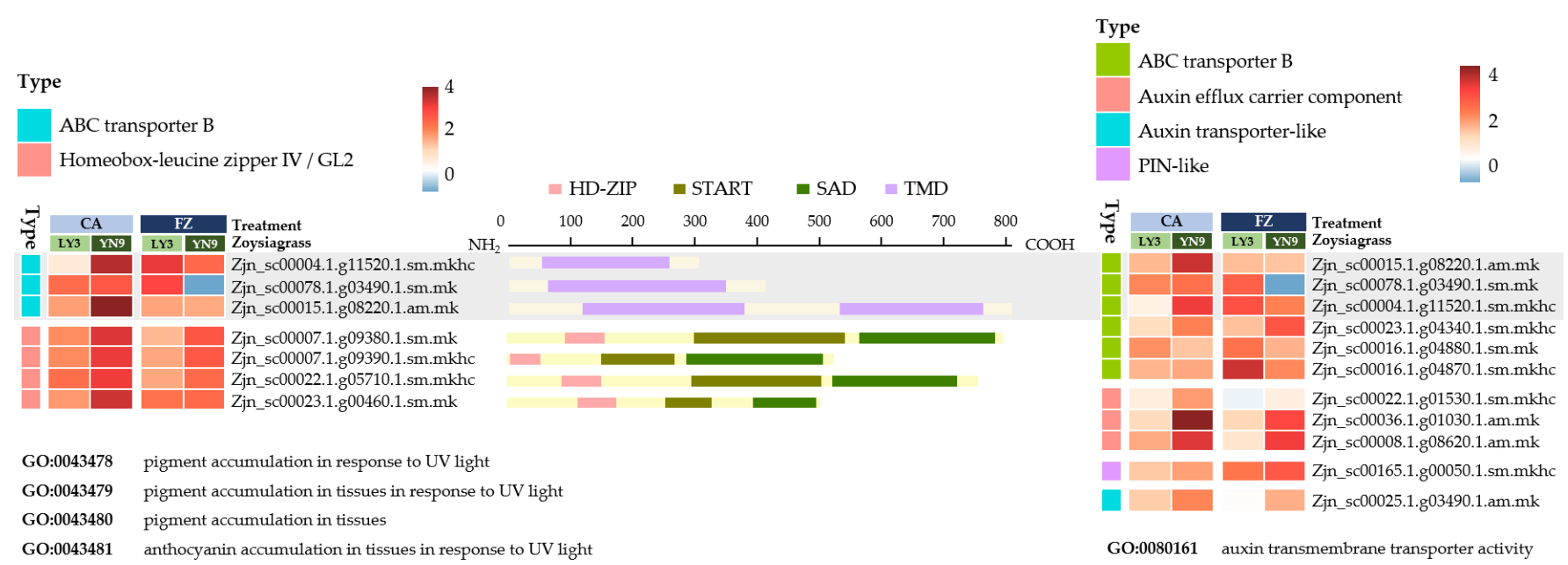

Figure 6. Expression variations and sequence structure of genes involved in pigment accumulation and auxin transmembrane transport in LY-3 and YN-9 after cold acclimation and freezing treatment. The heatmaps were drawn based on $\log _{2} \mathrm{FC}$ values. The grey rectangle highlighted the genes shared by GOs of pigment accumulation and auxin transmembrane transport. The protein domains were predicted with Pfam database using Interproscan.

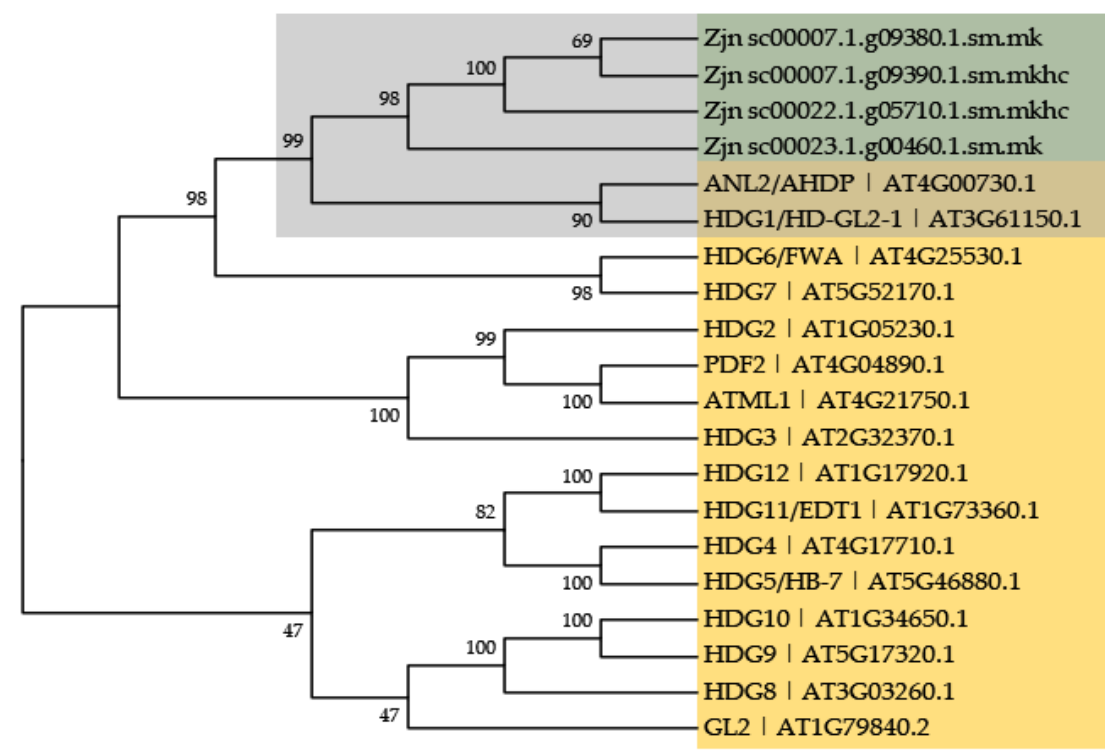

Figure 7. Phylogenetic analysis of the four Zoysia japonica HD-ZIP IV proteins (in green) associated with pigmentation and 16 Arabidopsis thaliana HD-ZIP IV members (in yellow). Multiple sequence alignment was performed using MUSCLE with default settings; Phylogenetic tree was constructed using Neighbor-Joining method with 1000 bootstrap replicates.

\subsubsection{ABCB Transmembrane Transporter}

According to a BLAST search through the RAP and Swissprot database, the three ABCB genes from the pigmentation GOs were homologous to ABCB 1 or 19 (Table S4). However, only one or two transmembrane domains (TMDs) were found in the three genes, indicating a lack of complete gene structure as reported in ABCB members, which typically contain two TMDs and two nucleotide-binding domains (NBDs) [38-41]. These three genes were also associated with two auxin transport-related GOs, "auxin transmembrane transporter activity" and "auxin efflux transmembrane transporter activity", which were also enriched with genes uniquely up-regulated in YN-9 ( $\log _{2} \mathrm{FC}>1$ and $p$-value adjusted 0.05) (Figure 6). An $A B C B 8$ homolog "Zjn_sc00023.1.g04340.1.sm.mkhc" was also found to be persistently up-regulated following cold acclimation and freezing treatment. 


\subsection{Expression Variations of Anthocyanin-Synthesis Genes}

Using BLAST against the rice anthocyanin-synthesis (ATH-syn) gene sequences, 45 matched genes were retrieved from the zoysiagrass database. Seven of these were found to be false positive genes after being cross-checked against the TAIR, RAP, and Swissprot databases. Among the remaining 38 ATH-syn genes, 3 encode Anthocyanidin synthase (ANS), 5 encode Chalcone synthase (CHS), 2 encode Caffeic acid 3-O-methyltransferase (COMT), 3 encode Dihydroflavanol-4-reductase (DFR), 6 encode Flavanone 3-hydroxylase (F3H), 6 encode Phenylalanine ammonia-lyase (PAL), and 13 encode UDP-glucosyltransferase (UGT) (Table S5).

LY-3 had 9 ATH-syn genes that were significantly up-regulated $\left(\log _{2} \mathrm{FC}>1\right.$ and $p$-value adjusted $<0.05)$ following cold acclimation and freezing treatments, whereas YN-9 had 16 ATH-syn genes that were significantly up-regulated following cold acclimation and freezing treatments, respectively. The differences in gene expression changes between the two zoysiagrass biotypes were most evident in PAL genes, with three and four of the total six PALs in YN-9 significantly up-regulated after cold acclimation and freezing treatment, respectively, whereas no PAL genes in LY-3 showed significant up-regulation after either cold acclimation or freezing treatment (Figure 8).
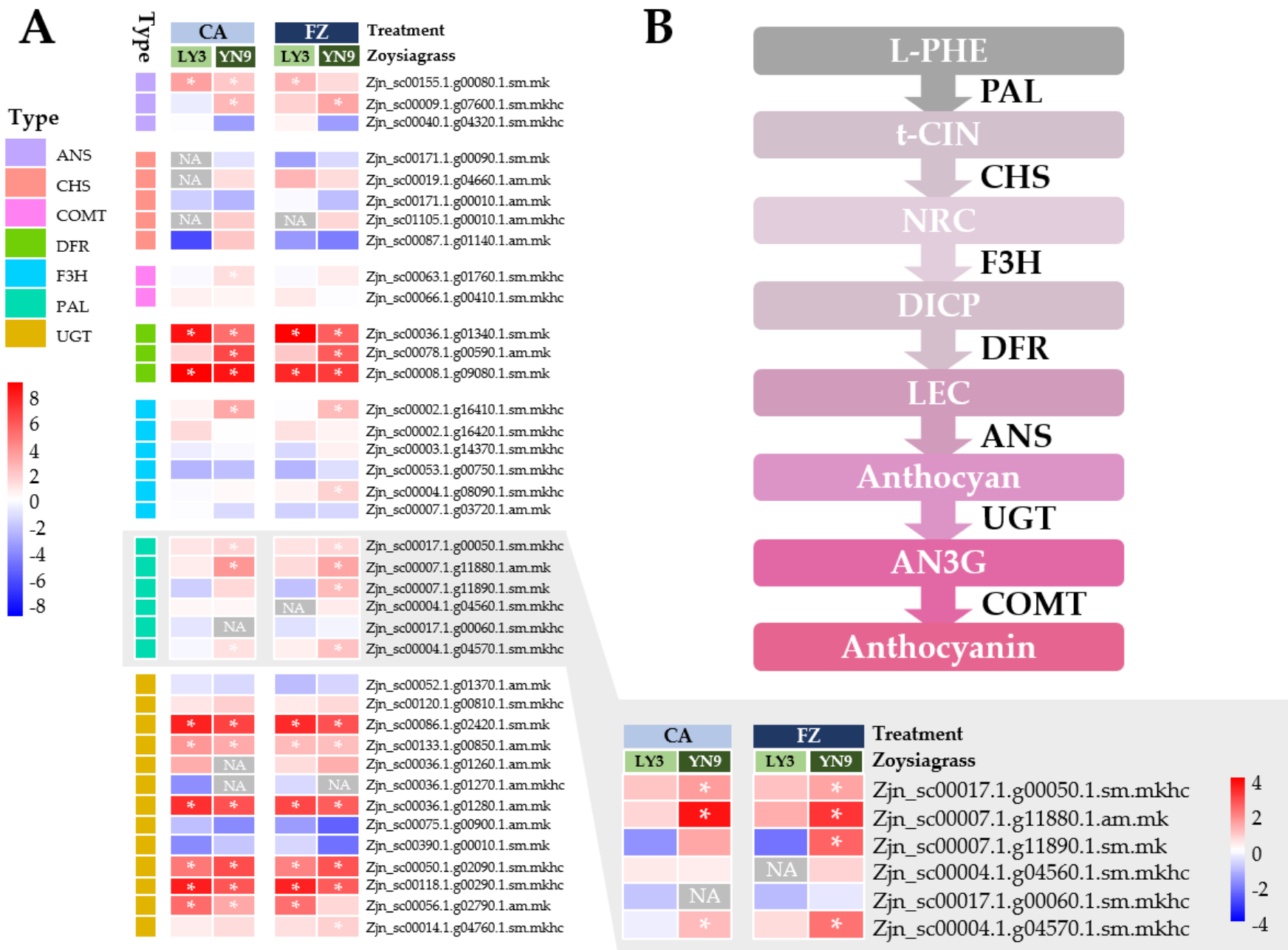

Figure 8. Expression variations of anthocyanin-biosynthesis genes in LY-3 and YN-9 after cold acclimation (CA) and freezing (FZ) treatment. (A) Heatmap based on $\log _{2} \mathrm{FC}$ of anthocyanin-biosynthesis genes, ${ }^{*}$ indicates up-regulated genes with $\log _{2} \mathrm{FC}>1$ and $p$-value adjusted $<0.05$. (B) Global picture of anthocyanin biosynthesis in plant cells. 


\subsection{Down-Regulation of Zinc Transporters in YN-9}

Genes uniquely down-regulated in $\mathrm{YN}-9\left(\log _{2} \mathrm{FC}<-2\right.$ and $p$-value adjusted $\left.<0.05\right)$ after cold acclimation were enriched in three GOs associated with zinc ion transport (GO0005385: zinc ion transmembrane transporter activity, GO0071577: zinc ion transmembrane transport, GO0006829: zinc ion transport), which all includes the same eight genes. According to a BLAST search in the Swissprot database, these genes encode proteins that are homologous to zinc transporters 3, 7, or 8, or $\mathrm{Fe}^{2+}$ transport protein 1 (Table S6). The Interproscan results also verified that all the eight genes contained the gene structure of zinc-regulated transporters and iron-regulated transporter-like proteins (ZIPs) (Figure 9). According to DEGSeq2 results, the expression levels of the eight ZIP genes in YN-9 decreased by 5-354 times after cold acclimation and by 3-70 times after freezing treatment. Seven of these genes remained significantly down-regulated in $\mathrm{YN}-9$ after freezing treatment and were included in GO0005385 (zinc ion transmembrane transporter activity) which was among the GOs enriched with genes uniquely down-regulated in $\mathrm{YN}-9$ after freezing treatment, while only one of them was significantly down-regulated in LY-3 after freezing treatment (Figure 9).
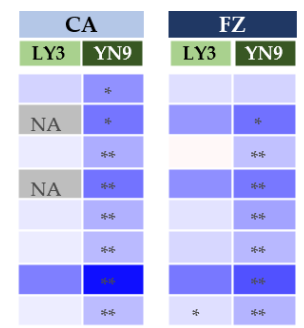

Zjn_sc00010.1.g04600.1.sm.mk

Zjn_sc00010.1.g04610.1.am.mk

Zjn_sc00016.1.g02640.1.sm.mkhc

Zjn sc00065.1.g00010.1.am.mk

Zjn_sc00120.1.g00520.1.am.mk

Zjn_sc00120.1.g00540.1.am.mk

Zjn_sc00229.1.g00030.1.am.mk

Zjn_sc06271.1.g00010.1.sm.mk

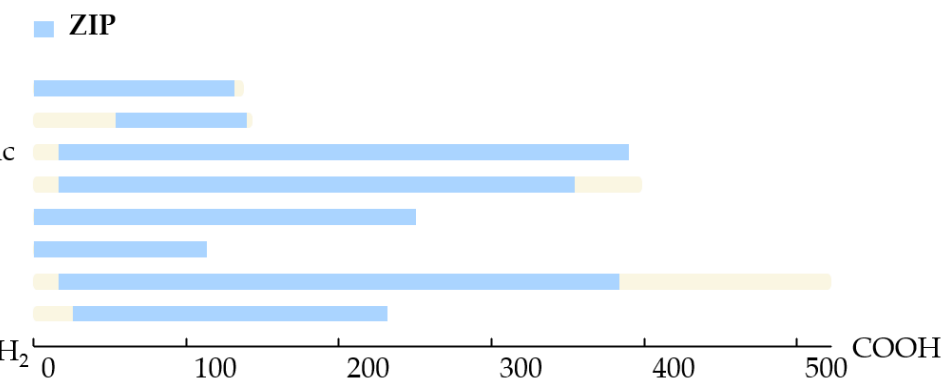

Figure 9. Expression variations and sequence structures of ZIP genes in LY-3 and YN-9 after cold acclimation and freezing treatment. The heatmaps were drawn based on $\log _{2} \mathrm{FC}$ values, ${ }^{*}$ and ${ }^{* *}$ indicate significant differences at $p$-values $<0.05$ and 0.01 , respectively. The sequence structures were drawn based on Interproscan analysis with PANTHER database.

\section{Discussion}

\subsection{Anthocyanin Accumulation and Cold-Tolerance in YN-9}

Anthocyanins are a group of flavonoid-type secondary metabolites found throughout the plant kingdom. They play a crucial role in plant reproduction by attracting pollinators and seed dispersers through pigmentation in flowers, fruits and vegetative tissues [42], and they also serve as protectants against a variety of abiotic and biotic stresses [23,43-47]. Anthocyanins accumulate in response to abiotic stresses such as drought, cold, and high light intensity. Low temperature, in particular, enhances anthocyanin accumulation, the abundance of anthocyanin-biosynthesis enzymes, and the expression of anthocyaninbiosynthesis genes in several plant species $[21,23-25,43,48-54]$. Although the exact mechanisms by which anthocyanins enhance cold tolerance is undetermined, a positive association between anthocyanin accumulation and cold tolerance has been well established in a variety of plant species [22-24,55,56]. Here, a zoysiagrass biotype YueNong No. 9 (YN-9) was collected in Lvshun West Station in Dalian, China (121 $\left.{ }^{\circ} 7^{\prime} 48^{\prime \prime} \mathrm{E}, 38^{\circ} 49^{\prime} 12^{\prime \prime} \mathrm{N}\right)$, where the average annual winter temperature ranges from $-3{ }^{\circ} \mathrm{C}$ to $-4{ }^{\circ} \mathrm{C}$ and the lowest temperature can reach $-18{ }^{\circ} \mathrm{C}$. As a result, we hypothesize that YN-9 is a cold-tolerant biotype that evolved as a result of long-term natural low-temperature screening. In comparison to LanYin No. 3 (LY-3), the most extensively utilized Z. japonica cultivar for urban greening and sports fields in southern China, YN-9 showed a larger portion of red to reddish-purple leaves, higher foliage anthocyanin content, and enhanced chilling tolerance when exposed to the natural low temperature through the winter in Guangzhou (Figure 2). Given the positive correlation between anthocyanin content and cold tolerance, we speculate that the ability to accumulate anthocyanins more efficiently at low temperatures is 
a cold-acclimation mechanism evolved by YN-9 to cope with the severe winter weather in its growing site, allowing it to acquire better cold tolerance than LY-3. The extent to which anthocyanin accumulation contributes to YN-9's cold tolerance and the molecular mechanism by which anthocyanin influences low-temperature responses in YN-9 remain unanswered questions that will be a major focus of our future research.

\subsection{Enhanced Expressions of Genes Associated with Anthocyanin Accumulation in YN-9}

3.2.1. Anthocyanin-Biosynthesis Genes

The primary regulators of anthocyanin biosynthesis are structural and regulatory genes [57-71]. The structural genes encode enzymes involved in anthocyanin biosynthesis, including phenylalanine ammonia lyase (PAL), cinnamate 4-hydroxylase $(\mathrm{C} 4 \mathrm{H})$, chalcone synthase (CHS), flavanone 3-hydroxylase (F3H), dihydroflavonol 4-reductase (DFR), anthocyanidin synthase (ANS), and UDP-glucose: flavonoid 3-O-glucosyltransferase (UFGT) [42] Here, up-regulation of anthocyanin-biosynthesis genes were detected in both LY-3 and YN-9 after cold acclimation and/or freezing treatment. YN-9 had a larger amount of up-regulated genes than LY-3, and these genes that were uniquely up-regulated in YN-9 mainly belonged to PALs (Figure 8). PAL is a rate-limited enzyme engaged in the phenylalanine metabolism and catalyzes the conversion of L-phenylalanine to trans-cinnamic acid in the anthocyanin biosynthesis pathway [42]. There is enough evidence to suggest that the expression levels of $P A L$ genes are associated to anthocyanin accumulation in plant tissues [72-77]. The pal1 pal2 mutant Arabidopsis was reported to accumulate little anthocyanin pigments when plants were grown in under-fertilized and relatively lowtemperature conditions, suggesting a redundant and important role of these two genes in anthocyanin biosynthesis [78]. More particularly, PAL genes have been shown to play a specialized role in anthocyanin biosynthesis in response to low temperature, through investigation of these genes using gene expression profiling, enzymatic activity assessment, omic survey and promoter functional analysis. A previous research has shown that low temperature can trigger transcription of PAL genes, which leads to enhanced PAL activity in Arabidopsis [79]. An integrated transcriptomic and proteomic analysis indicated that two anthocyanin-biosynthesis genes EjPAL and EjANS might play a vital role in the cold response of Eriobotrya japonica. The PAL promoter in Fagopyrum tataricum (PFtPAL) was shown to be capable of conferring cold-induced expression through the investigation of the GUS activity changes in PFtPAL::GUS transformed tobacco leaves at low temperature [80]. Here, we found that $P A L$ genes were uniquely up-regulated in YN-9 after cold acclimation and freezing treatment, while no PAL gene was observed to be up-regulated in LY-3 either after cold acclimation or freezing treatment. The increased low-temperature sensitivity of $P A L$ gene may be one of the factors boosting anthocyanin production in YN-9, resulting in a higher anthocyanin content and better cold-tolerance than LY-3.

\subsubsection{HD-IV Transcription Factors}

Plant HD-ZIP transcription factors share a structural character of a leucine zipper motif down-stream of the homeodomain (HD) and can be classified into four subfamilies: HD-ZIP I, HD-ZIP II, HD-ZIP III, and HD-ZIP IV [81]. HD-ZIP IV subfamily was also known as HD-ZIP GL2 or simply GL2 family after its first identified member, the Arabidopsis GLABRA2 protein (AT1G79840). HD-ZIP IV members consist of a START (steroidogenic acute regulatory protein-related lipid transfer) domain connected to a conserved SAD (START-adjacent domain) and is primarily engaged in root growth, plant cell differentiation, trichome formation, and anthocyanin accumulation [82-85]. Here, genes uniquely up-regulated in YN-9 $\left(\log _{2} \mathrm{FC}>2\right.$ and $p$-value adjusted $\left.<0.05\right)$ were enriched in four GO categories associated with pigment accumulation (Figure 6). Four of these genes, Zjn_sc00007.1.g09380.1.sm.mk, Zjn_sc00007.1.g09390.1.sm.mkhc, Zjn_sc00022.1.g05710.1.sm.mkhc and Zjn_sc00023.1.g00460.1.sm.mk belong to HD IV (HD-GLABRA2 group) and all shared high resemblance with TAIR database is AtANL2 (AT4G00730) (Figure 7), which has been reported to be strongly associated with anthocyanin accumulation and transport in Ara- 
bidopsis. Arabidopsis anl2 mutants accumulate significantly lower levels of anthocyanin in subepidermal and epidermal cells in the shoot and have numerous additional cells between the epidermal and cortical layers in the root [86,87]. It is possible that the ANL2 homologs in zoysiagrass shared similar function and promoted anthocyanin accumulation in leaves of YN-9.

\subsection{Enhanced Expressions of Anthocyanin Transport Genes in YN-9}

Anthocyanins are synthesized in cytosol and endoplasmic reticulum membrane system, then transported into vacuoles via ABC transporters located in tonoplast [39,88-92]. In this study, three genes that were uniquely up-regulated in YN-9 lay in the overlap of auxin transport and pigmentation accumulation GOs. Although the expressions of these genes increased dramatically in YN-9 after cold acclimation, their expressions dropped back or even showed down-regulation after freezing treatment. In LY-3, although the expressions of these genes were less up-regulated than in YN-9 after cold acclimation, they continued to rise after freezing treatment. This implies that these genes in both YN-9 and LY-3 may respond to low temperatures, but at distinct rates and patterns. These genes were found to be the most similar to ABCB1 or 19 when compared to databases. ABCB1 and 19 are auxin efflux carriers involved in the accumulation of anthocyanin [93,94]. However, Interproscan analysis indicated that the proteins produced by these three genes do not have the complete ABCB structural domain. As a result, it was unclear if they truly play a role in anthocyanin transport and accumulation in zoysiagrass.

According to a study on Zijuan Tea (Camellia sinensis var. kitamura), the abundance of the ABC transporter B8 (ABCB8) as well as its mRNA expression level in purple leaves was significantly higher than in green leaves, implying that ABCB8 may be involved in the active transport of anthocyanin from cytoplasm to vacuoles, resulting in anthocyanin accumulation in cell vacuoles [95]. The homologous gene of this $A B C B 8$ in zoysiagrass, "Zjn_sc00023.1.g04340.1.sm.mkhc", was also uniquely over-expressed in YN-9 both after cold acclimation and freezing treatment, implying a possible role of this gene in lowtemperature-induced anthocyanin transport and accumulation in cell vacuoles (Figure 6).

\subsection{Down-Regulation of Zinc Transporters Genes in YN-9}

Zinc is essential in the formation of chlorophyll, auxin and some carbohydrates, conversion of starches to sugars and its presence in plant tissue helps the plant to withstand cold temperatures [96]. According to a study on anthocyanin-rich purple corn, interacting with $\mathrm{Zn}$ /alginate slowed chemical degradation of anthocyanin [97]. GO Enrichment analysis showed that genes uniquely down-regulated in YN-9 were enriched in GO categories associated with zinc ion transport. The expression levels of the eight genes included in these GOs were not only significantly down-regulated after cold acclimation, but remained so after freezing treatment (Figure 9). Previous studies showed that genes in rice that were homologous to those eight genes were engaged in the distribution of $\mathrm{Zn}^{2+}$ from tissue to tissue $[98,99]$. Activation and over-expression of OsZIP8 altered the zinc distribution in rice plants, causing lower levels in shoots and mature seeds, but an increase in the roots. When applied with excess zinc, transgenic rice contained less zinc in their shoots but accumulated more in the roots [98]. As a result, we postulated that down-regulation of ZIPS in YN-9 prevented Zinc efflux from leaf cells to other tissues, and the zinc ions maintained in the leaf cells interacted with anthocyanin and protected them from degradation.

\subsection{A Proposed Regulation Network of Anthocyanin Accumulation in YN-9}

Different levels of tissue pigmentation were observed across zoysiagrass cultivars, for example, 'Zenith', 'Millock', and 'Greenzoa' have green spikes and stolons, while 'Anyangjungji', 'Meyer', and 'Senock' develop purple colors in the same tissues, and anthocyanin accumulation is most likely to be responsible for this purple pigmentation [10,100-102]. Although a positive correlation has been well established between anthocyanin accumulation and cold tolerance in many plant species $[22-24,55,56]$, no research has yet correlated an- 
thocyanin accumulation with cold tolerance in zoysiagrass. Here, we discovered that YN-9 outperformed LY-3 in terms of cold endurance (Figure 3), and the leaves exhibited purple pigmentation and anthocyanin accumulation under natural low temperature (Figure 2). According to transcriptomic profiling, YN-9 showed a series of gene responses favoring anthocyanin accumulation after both cold domestication and freezing treatments, including the up-regulation of PALs favoring anthocyanin synthesis, the up-regulation of HD-ZIP $I V$ genes favoring anthocyanin accumulation, the up-regulation of $A B C B 8$ favoring anthocyanin translocation from cytosol to vacuole, and the down-regulation of ZIPS which slowed the efflux of zinc ions from leaf cells, and therefore improved the chemical stability of anthocyanin within the cells (Figure 10). All of these findings are consistent with YN-9's capacity to accumulate anthocyanin more effectively during the winter, suggesting that low temperature-induced gene responses that improve anthocyanin accumulation may be a coping strategy that YN-9 adopted to endure the harsh winter in northeast China (Figure 1).

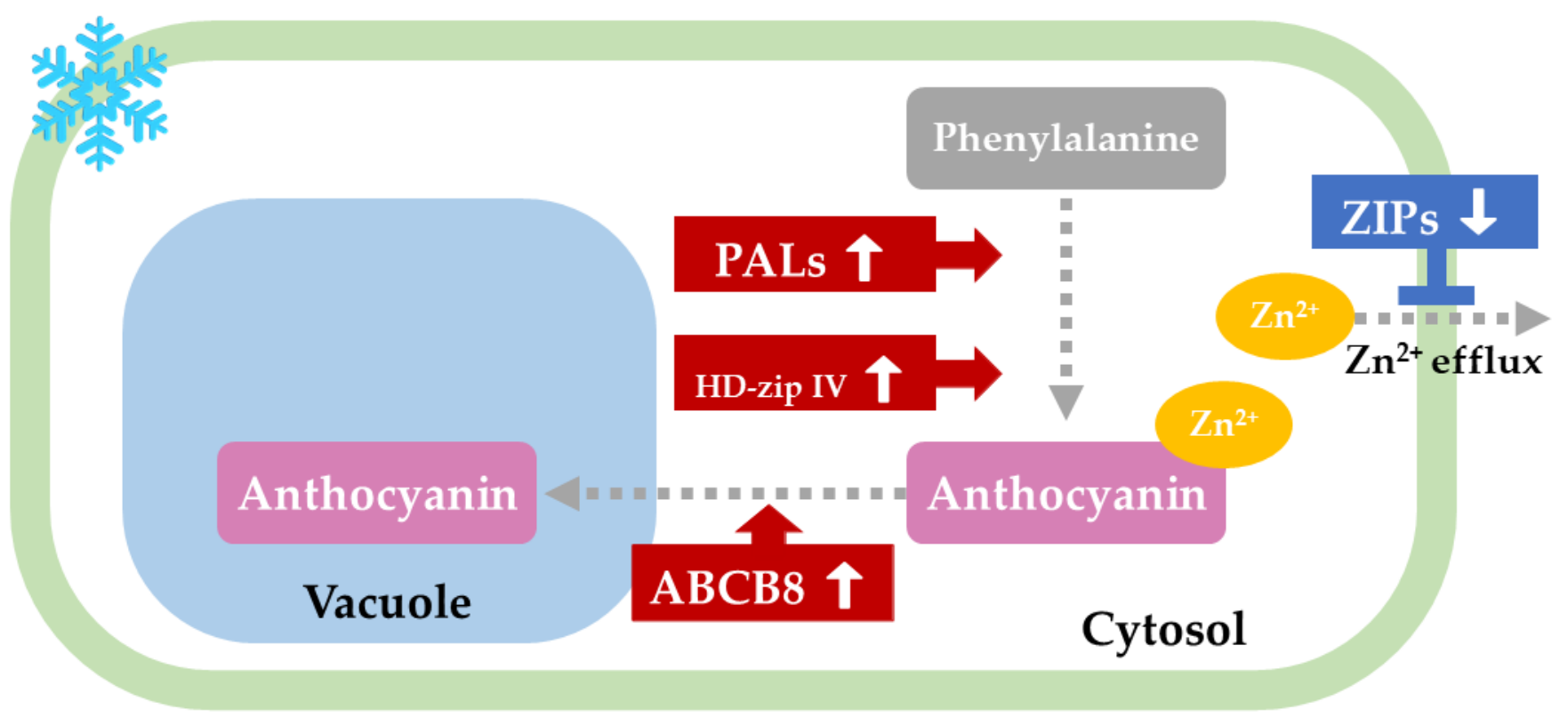

Figure 10. A proposed schematic representation of how low temperature-induced fluctuations of transcript abundance regulate anthocyanin synthesis, transport, and accumulation in YN-9 leaf cells. $\rightarrow$ and $\dashv$ indicate positive and negative regulation of biological processes, respectively.

\subsection{Future Outlook}

Much more research is required to validate the proposed network, for example, a more detailed profiling of the expression fluctuations of candidate genes in zoysiagrass over time after being exposed to low temperature using Real-Time PCR, a more comprehensive investigation on the correlation between cold tolerance and anthocyanin accumulation in larger populations of zoysiagrass, a survey of trait segregation in the YN-9 progenies, functional analysis to verify the impact of the candidate genes on anthocyanin synthesis and cold tolerance by altering their expressions in zoysiagrass, such as gene over-expression in LY-3 using gene transformation, or gene knock-out/knockdown in YN-9 using CRISPR-Cas9/RNA interference. Given that genetic engineers have attempted to improve anthocyanin accumulation and cold tolerance in several plant species by introducing anthocyanin biosynthesis genes or regulatory transcription factors (TFs) [103-105], this work provides not just novel plant material for zoysiagrass breeding, but also new insights and potential genes for engineering breeding. 


\section{Materials and Methods}

\subsection{Plant Materials}

The Zoysia japonica biotype YueNong No. 9 (YN-9) were collected from Lvshun west station, Dalian, China $\left(38^{\circ} 49^{\prime} 12^{\prime \prime} \mathrm{N}, 121^{\circ} 7^{\prime} 48^{\prime \prime}\right.$ E) on 7 July 2019 (Figure 1$)$. The $Z$. japonica cultivar LanYin No. 3 (LY-3) were provided by Guangzhou Landscaping Company. Both zoysiagrasses were propagated vegetatively with stolons in a soil mixture of $1 / 2$ Jiffy soil (Jiffy Products International AS, Stange, Norway) and $1 / 2$ vermiculite in the College of Agriculture, South China Agricultural University ( $23^{\circ} 9^{\prime} 38^{\prime \prime} \mathrm{N}, 113^{\circ} 21^{\prime} 32^{\prime \prime} \mathrm{E}$ ). The zoysiagrass biotypes were exposed to the natural low temperature in Guangzhou from October, 2020 to February 2021. The cold acclimation and freezing treatment of the zoysiagrass biotypes were performed in September 2021.

\subsection{Anthocyanin Assay}

The assessment of anthocyanin content in zoysiagrass leaves was developed from the method reported by Oancea et al. in 2012 [50]. Here, $0.5 \mathrm{~g}$ fresh leaves were grounded with liquid nitrogen and homogenized using extraction buffer of ethanol: $0.1 \mathrm{~mol} / \mathrm{L} \mathrm{HCl}$ (95:15). Extraction was facilitated by occasional shaking for $2 \mathrm{~h}$. The obtained extracts were filtered and centrifuged at $8000 \mathrm{rpm}$ at $4{ }^{\circ} \mathrm{C}$ for $10 \mathrm{~min}$. The absorbance of the solution was measured using a spectrophotometer at $530 \mathrm{~nm}, 620 \mathrm{~nm}$ and $650 \mathrm{~nm}$. The anthocyanin content was calculated using the following equation:

$$
\mathrm{C}=\frac{\mathrm{A} \times \mathrm{V}}{\mathrm{a} \times \mathrm{l} \times \mathrm{w}}
$$

where: C: anthocyanin content (mg/100g fresh weight)A: (OD $\left.530 \mathrm{~nm}-\mathrm{OD}_{620 \mathrm{~nm}}\right)-$ $0.1\left(\mathrm{OD}_{650 \mathrm{~nm}}-\mathrm{OD}_{620 \mathrm{~nm}}\right)$; V: volume of tested solution; a: molar absorption coefficient; 1: path-length (cm); w: sample fresh weight (100 g).

\subsection{Cold tolerance Assessment}

LY-3 and YN-9 sods of $7.5 \mathrm{~cm}$ in diameter were transplanted into pots of $10 \mathrm{~cm} \times 10 \mathrm{~cm}$ $\times 14 \mathrm{~cm}$, and filled with a soil mixture of $1 / 2$ Jiffy soil and $1 / 2$ vermiculite. One month after transplanted to the pots, both zoysiagrass biotypes were selected for cold treatment. The zoysiagrass was first subjected to a 3-day cold acclimation at $4{ }^{\circ} \mathrm{C}$, followed by a 2-day freezing treatment at $-4{ }^{\circ} \mathrm{C}$. The temperature was progressively raised to $25^{\circ} \mathrm{C}$ at a rate of $2{ }^{\circ} \mathrm{C}$ per hour, and the grasses were grown at this temperature for 2 additional weeks to assess the survival rate and dark green color index (DGCI) values. The entire treatment was carried out at $60 \%$ humidity under a $16 / 8 \mathrm{~h}$ (light/dark) photoperiod with a photon flux density (PFD) of $180 \mu \mathrm{mol} \cdot \mathrm{m}^{-2} \cdot \mathrm{s}^{-1}$.

The DGCI value is an indicator of dark green color that is calculated from the average of the converted HSB values: the greater the value, the more the leaf color is associated with dark green [106,107]. Each pot was photographed before and after treatment at the same time and in the same location with the same lighting. ImageJ (https://imagej.nih.gov/ij/, accessed on 29 December 2021) was used to identify RGB values in each photo, which were then converted into hue $(\mathrm{H})$, saturation $(\mathrm{S})$, and brightness $(\mathrm{B})$. The DGCI values of each image were calculated using the following equation:

$$
\mathrm{DGCI}=\frac{\left[\frac{\mathrm{H}-60}{60}+(1-\mathrm{S})+(1-\mathrm{B})\right]}{3}
$$

\subsection{RNA Extraction, cDNA Library Construction and Illumina Sequencing}

Fresh leaves were harvested for RNA extraction three times: once before treatment, once when cold acclimation was complete, and once after a $24 \mathrm{~h}$ freezing treatment. Total RNA was isolated using RNAprep Pure Plant Kit (TianGen Biotech, Beijing, China) from the collected leaves of LY-3 and YN-9, respectively. The RNA was electrophoresed on 1\% agarose gels for monitoring RNA degradation and contamination. RNA purity, concen- 
tration, and integrity were further assessed using Qubit2.0 (Thermo Scientific, Waltham, MA, USA) and Agilent 2100 (Agilent Technologies, Santa Clara, CA, USA). A total of 18 RNA-Seq libraries ( 2 zoysiagrasses $\times 3$ sampling times $\times 3$ independent biological replicates) were constructed using the NEBNext ${ }^{\circledR}$ Ultra ${ }^{\mathrm{TM}}$ Directional RNA Library Prep Kit for Illumina ${ }^{\circledR}$ (NEB, USA), following the manufacturer's instructions. RNA-seq libraries were sequenced using the Illumina HiSeq X-ten platform at Beijing Genomics Institute.

\subsection{RNA Seq Analysis}

Raw sequencing reads were processed with a perl script to remove adapters and primers, and discard reads containing over $5 \%$ ambiguous base $\mathrm{N}$ or over $50 \%$ low quality bases (quality score < 10). The clean reads were mapped to the reference genome of Zoysia japonica cv. Nagirizaki downloaded from Zoysia Genome Database (http: / zoysia.kazusa.or. jp / , accessed on 29 December 2021) using HISAT2 [108,109]. Read counts were quantified using StringTie v2.0.4 [110]. Pairwise gene expression comparisons were performed using DESeq2 v1.26.0 [111]. Genes with FDR $<0.05$ and absolute value of $\log _{2}$ fold change $\left(\log _{2} F C\right)$ $>1$ were identified as differentially expressed genes (DEGs). DEGs were then selected based on multiple $\log _{2} \mathrm{FC}$ thresholds for GO and KEGG enrichment using the clusterProfiler $\mathrm{R}$ package [112]. The clean reads were deposited to Sequence Read Archive (SRA) database at National Center for Biotechnology Information (NCBI) under BioProject PRJNA788220.

\subsection{Anthocyanin-Synthesis Gene Profiling}

The rice anthocyanin-synthesis gene locus IDs were collected from an article published in 2021 by Ling et al. [113], and the gene sequences were obtained from the Rice Annotation Project Databases (RAP-DB, https: / / rapdb.dna.affrc.go.jp/tools / dump, accessed on 29 December 2021). BLAST was used to extract matching sequences from the zoysiagrass database, which were then compared with the TAIR, RAP-DB, and Swissprot databases to exclude false-positive sequences.

\subsection{Phylogenetic Analysis}

To determine the homology between the 4 Z. japonica HD-ZIP IV proteins and AtHDGL2 as well as AtANL2, 16 HD-ZIP IV protein sequences of Arabidopsis thaliana were aligned with the $4 Z$. japonica proteins using MUSCLE with default settings. Phylogenetic tree was constructed from the multiple alignments using Neighbor-Joining method with 1000 bootstrap replicates.

\subsection{Statistical Analysis}

All morphological and physiological data were analyzed using the IBM SPSS Statistics 23.0 software. Significance of differences between samples or treatments were evaluated by Duncan's multiple range test.

\section{Conclusions}

YueNong-9 (YN-9) is a Zoysia japonica biotype collected from northeast China where the winter temperature can drop to $-18{ }^{\circ} \mathrm{C}$. Using morphological, physiological, and transcriptomic approaches, the anthocyanin accumulation and cold tolerance were determined in YN-9 and LanYin-3 (LY-3), a popular Z. japonica cultivar in southern China. YN-9 demonstrated greater cold tolerance and anthocyanin accumulation under low temperature compared to LY-3. RNA-seq analysis revealed unique gene expression variations enhancing anthocyanin biosynthesis, transport, and accumulation, including up-regulation of PALs, HD-ZIP IVs, and ABCB8, and down-regulation of ZIPs. As a result, YN-9 is an ideal candidate for breeding cold-tolerant $Z$. japonica cultivars, and its unique low-temperatureinduced anthocyanin accumulation and gene responses provide ideas and candidate genes for the study of low-temperature tolerance mechanisms and genetic engineering breeding. In the future, more comprehensive gene expression profiling and molecular approaches such as gene over-expression and knock out/knock down will be necessary to validate the 
putative roles of the aforementioned candidate genes in anthocyanin accumulation and cold tolerance in zoysiagrass.

Supplementary Materials: The following are available online at https:/ / www.mdpi.com/article/ 10.3390/plants11030429/s1, Figure S1: Zoysia japonica ecotype Yuenong No. 9 (YN-9) collected from the edge of the tall fescue (Festuca arundinacea) lawn at Lvshun West Station, Dalian, China, Figure S2: Multiple sequences alignment of the four Zoysia japonica HD-Zip IV proteins associated with pigmentation and 16 Arabidopsis thaliana HD-Zip IV members, Table S1: Winter Temperature and Weather in Tianhe District, Guangzhou City, 2020-2021, Table S2: Clean read statistics and mapping rates, Table S3: BLAST results of the four pigmentation related HD-Zip IV proteins in zoysiagrass against TAIR protein database, Table S4: BLAST results of differentially expressed genes associated with GO0043478 in zoysiagrass, Table S5: BLAST results of anthocyanin biosynthesis associated genes in zoysiagrass, Table S6: BLAST results of zinc transport genes in zoysiagrass.

Author Contributions: Conceptualization, H.-X.J., L.-F.G. and S.C.; methodology, M.J., J.-F.Y. and Z.-H.W.; software, Z.-H.W. and L.-L.M.; validation, S.C. and L.-F.G.; formal analysis, Z.-H.W. and L.-L.M.; investigation, C.-C.W. and C.L.; resources, C.-C.W. and C.L.; data curation, Z.-H.W. and L.-L.M.; writing-original draft preparation, H.-X.J., M.J. and S.C.; writing-review and editing, L.-F.G. and J.-F.Y.; visualization, M.J., Z.-H.W. and X.-Y.N.; supervision, S.C. and L.-F.G.; project administration, H.-X.J., M.J., J.-F.Y. and S.C.; funding acquisition, L.-F.G. and S.C. All authors have read and agreed to the published version of the manuscript.

Funding: This research was funded by Key Research and Development Program of Guangzhou (grant number 202103000066), Science and Technology Program of Guangzhou (grant number 202002030366) and Guangzhou Landscaping Company (grant number GZLC-G201904).

Institutional Review Board Statement: Not applicable.

Informed Consent Statement: Not applicable.

Data Availability Statement: The clean reads produced by transcriptomic sequencing of YueNong No. 9 and LanYin No. 3 were deposited to Sequence Read Archive (SRA) database at National Center for Biotechnology Information (NCBI) under BioProject PRJNA788220.

Acknowledgments: We gratefully acknowledge Guangzhou Landscaping Company for providing the experimental material, zoysiagrass cultivar LanYin No. 3.

Conflicts of Interest: The authors declare no conflict of interest.

\section{References}

1. Anderson, S.J. Taxonomy of Zoysia (Poaceae) Morphological and Molecular Variation; Texas A\&M University: Dallas, TX, USA, 2000.

2. Shouliang, C.; Phillips, S.M. Zoysia Willdenow, Ges. Naturf. Freunde Berlin Neue Schriften 3: 440. 1801, nom. cons. In Flora of China; Zhengyi, W., Raven, P.H., Eds.; Science Press and Missouri Botanical Garden Pre: Beijing, China; St. Louis, MO, USA, 2013; pp. 496-498.

3. Braun, R.C.; Milla-Lewis, S.R.; Carbajal, E.M.; Schwartz, B.M.; Patton, A.J. Performance and playability of experimental low-input coarse-textured zoysiagrass in multiple climates. Grass Res. 2021, 1, 10. [CrossRef]

4. Meeks, M.; Kong, S.T.; Genovesi, A.D.; Smith, B.; Chandra, A. Low-input golf course putting green performance of fine-textured inter- and intra-specific zoysiagrass (Zoysia spp.). Int. Turfgrass Soc. Res. J. 2021, 1-12. [CrossRef]

5. Patton, A.J.; Schwartz, B.M.; Kenworthy, K.E. Zoysiagrass (Zoysia spp.) history, utilization, and improvement in the United States: A review. Crop Sci. 2017, 57, S-37-S-72. [CrossRef]

6. Chandra, A.; Milla-Lewis, S.; Yu, Q. An overview of molecular advances in zoysiagrass. Crop Sci. 2017, 57, S-73. [CrossRef]

7. Long, S.; Yan, F.; Yang, L.; Sun, Z.; Wei, S. Responses of Manila grass (Zoysia matrella) to chilling stress: From transcriptomics to physiology. PLoS ONE 2020, 15, e0235972. [CrossRef] [PubMed]

8. Lin, T.; Zhou, R.; Bi, B.; Song, L.; Chai, M.; Wang, Q.; Song, G. Analysis of a radiation-induced dwarf mutant of a warm-season turf grass reveals potential mechanisms involved in the dwarfing mutant. Sci. Rep. 2020, 10, 18913. [CrossRef]

9. Wang, R.; Wang, X.; Liu, K.; Zhang, X.J.; Zhang, L.Y.; Fan, S.J. Comparative transcriptome analysis of halophyte Zoysia macrostachya in response to salinity stress. Plants 2020, 9, 458. [CrossRef]

10. Ahn, J.H.; Kim, J.-S.; Kim, S.; Soh, H.Y.; Shin, H.; Jang, H.; Ryu, J.H.; Kim, A.; Yun, K.-Y.; Kim, S.; et al. De novo transcriptome analysis to identify anthocyanin biosynthesis genes responsible for tissue-specific pigmentation in zoysiagrass (Zoysia japonica Steud.). PLoS ONE 2015, 10, e0124497. [CrossRef] 
11. Zhu, C.; Ai, L.; Wang, L.; Yin, P.; Liu, C.; Li, S.; Zeng, H. De novo transcriptome analysis of Rhizoctonia solani AG1 IA strain early invasion in Zoysia japonica root. Front. Microbiol. 2016, 7, 708. [CrossRef]

12. Li, L.; He, X.; Zhao, F.; Zhu, C.; Zeng, H. WUS and PIN1-related genes undergo dynamic expressional change during organ regeneration in response to wounding in Zoysia japonica. Mol. Biol. Rep. 2018, 45, 1733-1744. [CrossRef]

13. Wang, J.; An, C.; Guo, H.; Yang, X.; Chen, J.; Zong, J.; Li, J.; Liu, J. Physiological and transcriptomic analyses reveal the mechanisms underlying the salt tolerance of Zoysia japonica Steud. BMC Plant Biol. 2020, 20, 114. [CrossRef] [PubMed]

14. Xie, Q.; Niu, J.; Xu, X.; Xu, L.; Zhang, Y.; Fan, B.; Liang, X.; Zhang, L.; Yin, S.; Han, L. De novo assembly of the Japanese lawngrass (Zoysia japonica Steud.) root transcriptome and identification of candidate unigenes related to early responses under salt stress. Front. Plant Sci. 2015, 6, 610. [CrossRef]

15. Wei, S.; Du, Z.; Gao, F.; Ke, X.; Li, J.; Liu, J.; Zhou, Y. Global transcriptome profiles of “Meyer" zoysiagrass in response to cold stress. PLoS ONE 2015, 10, e0131153. [CrossRef] [PubMed]

16. Chinnusamy, V.; Zhu, J.; Zhu, J. Cold stress regulation of gene expression in plants. Trends Plant Sci. 2007, 12, 444-451. [CrossRef]

17. Agarwal, P.K.; Agarwal, P.; Sopory, M.K.R.S.K. Role of DREB transcription factors in abiotic and biotic stress tolerance in plants. Plant Cell Rep. 2006, 25, 1263-1274. [CrossRef] [PubMed]

18. Lan, S.Y.S.; Ming, F.D. Effects of Calcium and calmodulin antagonists on chilling stress-induced proline accumulation in Jatropha curcas L. J. Plant Growth Regul. 2016, 35, 815-826. [CrossRef]

19. Naing, A.H.; Ai, T.N.; Lim, K.B.; Lee, I.J.; Kim, C.K.; Allen, R.D. Overexpression of rosea1 from snapdragon enhances anthocyanin accumulation and abiotic stress tolerance in transgenic tobacco. Front. Plant Sci. 2018, 9, 1070. [CrossRef] [PubMed]

20. Christie, P.J.; Alfenito, M.R.; Walbot, V. Impact of low-temperature stress on general phenylpropanoid and anthocyanin pathways: Enhancement of transcript abundance and anthocyanin pigmentation in maize seedlings. Planta 1994, 194, 541-549. [CrossRef]

21. Winkel-Shirley, B. Biosynthesis of flavonoids and effects of stress. Curr. Opin. Plant Biol. 2002, 5, 218-223. [CrossRef]

22. Zhang, Q.; Zhai, J.; Shao, L.; Lin, W.; Peng, C. Accumulation of anthocyanins: An adaptation strategy of Mikania micrantha to low temperature in winter. Front. Plant Sci. 2019, 10, 1049. [CrossRef]

23. Ahmed, N.U.; Park, J.I.; Jung, H.J.; Hur, Y.; Nou, I.S. Anthocyanin biosynthesis for cold and freezing stress tolerance and desirable color in Brassica rapa. Funct. Integr. Genom. 2015, 15, 383-394. [CrossRef]

24. Liu, Y.; Tikunov, Y.; Schouten, R.E.; Marcelis, L.F.M.; Visser, R.G.F.; Bovy, A. Anthocyanin biosynthesis and degradation mechanisms in Solanaceous vegetables: A review. Front. Chem. 2018, 6, 52. [CrossRef]

25. Naing, A.H.; Kim, C.K. Abiotic stress-induced anthocyanins in plants: Their role in tolerance to abiotic stresses. Physiol. Plant. 2021, 172, 1711-1723. [CrossRef] [PubMed]

26. Zuo, Z.F.; Gyu, H.; Quan, K.; Hong, C.; Young, M.; Hyeon, P.; Sun, J.; Kim, J. A novel basic helix-loop-helix transcription factor, ZjICE2 from Zoysia japonica confers abiotic stress tolerance to transgenic plants via activating the DREB/CBF regulon and enhancing ROS scavenging. Plant Mol. Biol. 2020, 102, 447-462. [CrossRef]

27. Sun, X.; Li, X.; Zhu, J.; Huang, N.; Bian, X.; Li, H.; Wang, L.; Han, L. Polyamines and ethylene metabolism during cold acclimation in zoysiagrass (Zoysia japonica Steud.). Acta Physiol. Plant 2020, 42, 1-10. [CrossRef]

28. Brown, J.M.; Dacosta, M.; Patton, A.J.; Livingston, D.P.; Bernstein, R.P.; Lu, J.; Dunne, J.C.; Arellano, C.; Milla-lewis, S.R. Differences in proteome response to cold acclimation in Zoysia japonica cultivars with different levels of freeze tolerance. Crop Sci. 2020, 60, 2744-2756. [CrossRef]

29. Zuo, Z.; Sun, H.; Lee, H.; Kang, H.; Zjice, Z. Identification of $b H L H$ genes through genome-wide association study and antisense expression of ZjbHLH076/ZjICE1 influence tolerance to low temperature and salinity in Zoysia japonica. Plant Sci. 2021, 313, 111088. [CrossRef] [PubMed]

30. Okeyo, D.O.; Fry, J.D.; Bremer, D.; Rajashekar, C.B.; Kennelly, M.; Chandra, A.; Genovesi, D.A.; Engelke, M.C. Freezing tolerance and seasonal color of experimental zoysiagrasses. Crop Sci. 2011, 51, 2858-2863. [CrossRef]

31. Hinton, J.D.; Livingston, D.P.; Miller, G.L.; Peacock, C.H.; Tuong, T. Freeze tolerance of nine zoysiagrass cultivars using natural cold acclimation and freeze chambers. HortScience 2012, 47, 112-115. [CrossRef]

32. Zuo, Z.; Kang, H.; Park, M.; Jeong, H.; Sun, H. Plant Science Zoysia japonica MYC type transcription factor ZjICE1 regulates cold tolerance in transgenic Arabidopsis. Plant Sci. 2019, 289, 110254. [CrossRef]

33. Ji, Y.; Dae, K.; Yang, H.; Young, M.; Hyeon, P.; Sun, J.; Soon, P.; Hong, S.; Kang, G.; Gai, A.I.; et al. Overexpression of Zoysia ZjCIGR1 gene confers cold stress resistance to zoysiagrass. Plant Biotechnol. Rep. 2020, 14, 21-31. [CrossRef]

34. Xuan, J.; Song, Y.; Zhang, H.; Liu, J.; Guo, Z.; Hua, Y. Comparative proteomic analysis of the stolon cold stress response between the C4 perennial grass species Zoysia japonica and Zoysia matrella. PLoS ONE 2013, 8, e75705. [CrossRef]

35. Wang, Y.; Yang, Z.M.; Zhang, Q.F.; Li, J.L. Enhanced chilling tolerance in Zoysia matrella by pre-treatment with salicylic acid, calcium chloride, hydrogen peroxide or 6-benzylaminopurine. Biol. Plant. 2009, 53, 179-182. [CrossRef]

36. Brown, J.M.; Yu, X.; Patton, A.J.; Holloway, H.M.P.; Arellano, C.; Tuong, T.D.; Livingston, D.P.; Schwartz, B.M.; Milla-lewis, S.R. Identification of QTL associated with cold acclimation and freezing tolerance in Zoysia japonica. Crop Sci. 2021, 61, 3044-3055. [CrossRef]

37. Zuo, Z.F.; Kang, H.G.; Park, M.Y.; Jeong, H.; Sun, H.J.; Yang, D.H.; Lee, Y.E.; Song, P.S.; Lee, H.Y. Overexpression of ICE1, a regulator of cold-induced transcriptome, confers cold tolerance to transgenic Zoysia japonica. J. Plant Biol. 2019, 62, 137-146. [CrossRef] 
38. Andolfo, G.; Ruocco, M.; Di Donato, A.; Frusciante, L.; Lorito, M.; Scala, F.; Ercolano, M.R. Genetic variability and evolutionary diversification of membrane ABC transporters in plants. BMC Plant Biol. 2015, 15, 51. [CrossRef]

39. Dean, M.; Annilo, T. Evolution of the ATP-binding cassette (ABC) transporter superfamily in vertebrates. Annu. Rev. Genomics Hum. Genet. 2005, 6, 123-142. [CrossRef]

40. Theodoulou, F.L. Plant ABC transporters. Biochim. Biophys. Acta-Biomembr. 2000, 1465, 79-103. [CrossRef]

41. Lane, T.S.; Rempe, C.S.; Davitt, J.; Staton, M.E.; Peng, Y.; Soltis, D.E.; Melkonian, M.; Deyholos, M.; Leebens-Mack, J.H.; Chase, M.; et al. Diversity of $A B C$ transporter genes across the plant kingdom and their potential utility in biotechnology. BMC Biotechnol. 2016, 16, 47. [CrossRef]

42. Winkel-Shirley, B. Flavonoid biosynthesis. A colorful model for genetics, biochemistry, cell biology, and biotechnology. Plant Physiol. 2001, 126, 485-493. [CrossRef]

43. Dixon, R.A.; Paiva, N.L. Stress-induced phenylpropanoid metabolism. Plant Cell 1995, 7, 1085-1097. [CrossRef] [PubMed]

44. Moustaka, J.; Tanou, G.; Giannakoula, A.; Adamakis, I.S.; Panteris, E.; Eleftheriou, E.P.; Moustakas, M. Anthocyanin accumulation in poinsettia leaves and its functional role in photo-oxidative stress. Environ. Exp. Bot. 2020, 175, 104065. [CrossRef]

45. Li, X.; Ahammed, G.J.; Zhang, X.-N.; Zhang, L.; Yan, P.; Zhang, L.; Fu, J.; Han, W. Melatonin-mediated regulation of anthocyanin biosynthesis and antioxidant defense confer tolerance to arsenic stress in Camellia sinensis L. J. Hazard. Mater. 2021, $403,123922$. [CrossRef] [PubMed]

46. Teng, H.; Mi, Y.; Cao, H.; Chen, L. Enzymatic acylation of raspberry anthocyanin: Evaluations on its stability and oxidative stress prevention. Food Chem. 2022, 372, 130766. [CrossRef] [PubMed]

47. Hinojosa-Gómez, J.; Martín-Hernández, C.S.; Heredia, J.B.; León-Félix, J.; Osuna-Enciso, T.; Muy-Rangel, M.D. Anthocyanin induction by drought stress in the calyx of Roselle cultivars. Molecules 2020, 25, 1555. [CrossRef]

48. Zhang, S.; Zhang, A.; Wu, X.; Zhu, Z.; Yang, Z.; Zhu, Y.; Zha, D. Transcriptome analysis revealed expression of genes related to anthocyanin biosynthesis in eggplant (Solanum melongena L.) under high-temperature stress. BMC Plant Biol. 2019, 19, 387. [CrossRef]

49. Gao, J.; Chen, B.; Lin, H.; Liu, Y.; Wei, Y.; Chen, F.; Li, W. Identification and characterization of the glutathione S-Transferase (GST) family in radish reveals a likely role in anthocyanin biosynthesis and heavy metal stress tolerance. Gene 2020, 743, 144484. [CrossRef] [PubMed]

50. Nakabayashi, R.; Yonekura-Sakakibara, K.; Urano, K.; Suzuki, M.; Yamada, Y.; Nishizawa, T.; Matsuda, F.; Kojima, M.; Sakakibara, H.; Shinozaki, K.; et al. Enhancement of oxidative and drought tolerance in Arabidopsis by overaccumulation of antioxidant flavonoids. Plant J. 2014, 77, 367-379. [CrossRef]

51. Kaplan, F.; Kopka, J.; Sung, D.Y.; Zhao, W.; Popp, M.; Porat, R.; Guy, C.L. Transcript and metabolite profiling during cold acclimation of Arabidopsis reveals an intricate relationship of cold-regulated gene expression with modifications in metabolite content. Plant J. 2007, 50, 967-981. [CrossRef]

52. Crifò, T.; Puglisi, I.; Petrone, G.; Recupero, G.R.; Lo Piero, A.R. Expression analysis in response to low temperature stress in blood oranges: Implication of the flavonoid biosynthetic pathway. Gene 2011, 476, 1-9. [CrossRef]

53. Becker, C.; Klaering, H.P.; Kroh, L.W.; Krumbein, A. Cool-cultivated red leaf lettuce accumulates cyanidin-3-O-(6"-O- malonyl)glucoside and caffeoylmalic acid. Food Chem. 2014, 146, 404-411. [CrossRef] [PubMed]

54. Luo, Y.; Teng, S.; Yin, H.; Zhang, S.; Tuo, X.; Tran, L.S.P. Transcriptome analysis reveals roles of anthocyanin-and jasmonic acid-biosynthetic pathways in rapeseed in response to high light stress. Int. J. Mol. Sci. 2021, 22, 13027. [CrossRef] [PubMed]

55. Schulz, E.; Tohge, T.; Zuther, E.; Fernie, A.R.; Hincha, D.K. Natural variation in flavonol and anthocyanin metabolism during cold acclimation in Arabidopsis thaliana accessions. Plant Cell Environ. 2015, 38, 1658-1672. [CrossRef] [PubMed]

56. Schulz, E.; Tohge, T.; Zuther, E.; Fernie, A.R.; Hincha, D.K. Flavonoids are determinants of freezing tolerance and cold acclimation in Arabidopsis thaliana. Sci. Rep. 2016, 6, 34027. [CrossRef] [PubMed]

57. Quattrocchio, F.; Wing, J.F.; Leppen, H.T.C.; Mol, J.N.M.; Koes, R.E. Regulatory genes controlling anthocyanin pigmentation are functionally conserved among plant species and have distinct sets of target genes. Plant Cell 1993, 5, 1497-1512. [CrossRef]

58. Sun, C.; Deng, L.; Du, M.; Zhao, J.; Chen, Q.; Huang, T.; Jiang, H.; Li, C.-B.; Li, C. A transcriptional network promotes anthocyanin biosynthesis in tomato flesh. Mol. Plant 2020, 13, 42-58. [CrossRef] [PubMed]

59. Karppinen, K.; Lafferty, D.J.; Albert, N.W.; Mikkola, N.; McGhie, T.; Allan, A.C.; Afzal, B.M.; Häggman, H.; Espley, R.V.; Jaakola, L. MYBA and MYBPA transcription factors co-regulate anthocyanin biosynthesis in blue-coloured berries. New Phytol. 2021, 232, 1350-1367. [CrossRef]

60. Liu, Y.; Lin-Wang, K.; Espley, R.V.; Wang, L.; Li, Y.; Liu, Z.; Zhou, P.; Zeng, L.; Zhang, X.; Zhang, J.; et al. StMYB44 negatively regulates anthocyanin biosynthesis at high temperatures in tuber flesh of potato. J. Exp. Bot. 2019, 70, 3809-3824. [CrossRef]

61. Qiu, Z.; Wang, H.; Li, D.; Yu, B.; Hui, Q.; Yan, S.; Huang, Z.; Cui, X.; Cao, B. Identification of candidate HY5-dependent and -independent regulators of anthocyanin biosynthesis in tomato. Plant Cell Physiol. 2019, 60, 643-656. [CrossRef]

62. Chen, L.; Hu, B.; Qin, Y.; Hu, G.; Zhao, J. Advance of the negative regulation of anthocyanin biosynthesis by MYB transcription factors. Plant Physiol. Biochem. 2019, 136, 178-187. [CrossRef]

63. Xu, Z.S.; Yang, Q.Q.; Feng, K.; Yu, X.; Xiong, A.S. DcMYB113, a root-specific R2R3-MYB, conditions anthocyanin biosynthesis and modification in carrot. Plant Biotechnol. J. 2020, 18, 1585-1597. [CrossRef] [PubMed] 
64. Zheng, J.; Wu, H.; Zhu, H.; Huang, C.; Liu, C.; Chang, Y.; Kong, Z.; Zhou, Z.; Wang, G.; Lin, Y.; et al. Determining factors, regulation system, and domestication of anthocyanin biosynthesis in rice leaves. New Phytol. 2019, 223, 705-721. [CrossRef] [PubMed]

65. Iorizzo, M.; Cavagnaro, P.F.; Bostan, H.; Zhao, Y.; Zhang, J.; Simon, P.W. A cluster of MYB transcription factors regulates anthocyanin biosynthesis in Carrot (Daucus carota L.) root and petiole. Front. Plant Sci. Front. Plant Sci. 2019, 9, 1927. [CrossRef] [PubMed]

66. Wang, L.; Tang, W.; Hu, Y.; Zhang, Y.; Sun, J.; Guo, X.; Lu, H.; Yang, Y.; Fang, C.; Niu, X.; et al. A MYB/bHLH complex regulates tissue-specific anthocyanin biosynthesis in the inner pericarp of red-centered kiwifruit Actinidia chinensis cv. Hongyang. Plant J. 2019, 99, 359-378. [CrossRef]

67. Huang, D.; Tang, Z.; Fu, J.; Yuan, Y.; Deng, X.; Xu, Q. CsMYB3 and CsRuby1 form an 'activator-and-repressor' loop for the regulation of anthocyanin biosynthesis in Citrus. Plant Cell Physiol. 2020, 61, 318-330. [CrossRef]

68. Yang, L.; Pengbo, X.; Chen, G.; Wu, J.; Liu, Z.; Lian, H. FvbHLH9 functions as a positive regulator of anthocyanin biosynthesis by forming a HY5-bHLH9 transcription complex in strawberry fruits. Plant Cell Physiol. 2020, 61, 826-837. [CrossRef]

69. Ni, J.; Bai, S.; Zhao, Y.; Qian, M.; Tao, R.; Yin, L.; Gao, L.; Teng, Y. Ethylene response factors Pp4ERF24 and Pp12ERF96 regulate blue light-induced anthocyanin biosynthesis in 'Red Zaosu' pear fruits by interacting with MYB114. Plant Mol. Biol. 2019, 99, 67-78. [CrossRef]

70. Li, C.; Wu, J.; Hu, K.-D.; Wei, S.-W.; Sun, H.-Y.; Hu, L.-Y.; Han, Z.; Yao, G.-F.; Zhang, H. PyWRKY26 and PybHLH3 cotargeted the PyMYB114 promoter to regulate anthocyanin biosynthesis and transport in red-skinned pears. Hortic. Res. 2020, 7, 37. [CrossRef]

71. Tang, B.; Li, L.; Hu, Z.; Chen, Y.; Tan, T.; Jia, Y.; Xie, Q.; Chen, G. Anthocyanin accumulation and transcriptional regulation of anthocyanin biosynthesis in Purple Pepper. J. Agric. Food Chem. 2020, 68, 12152-12163. [CrossRef]

72. Han, M.; Yang, C.; Zhou, J.; Zhu, J.; Meng, J.; Shen, T.; Xin, Z.; Li, H. Analysis of flavonoids and anthocyanin biosynthesis-related genes expression reveals the mechanism of petal color fading of Malus hupehensis (Rosaceae). Braz. J. Bot. 2020, 43, 81-89. [CrossRef]

73. Li, W.-F.; Ning, G.-X.; Mao, J.; Guo, Z.-G.; Zhou, Q.; Chen, B.-H. Whole-genome DNA methylation patterns and complex associations with gene expression associated with anthocyanin biosynthesis in apple fruit skin. Planta 2019, 250, 1833-1847. [CrossRef] [PubMed]

74. Chen, X.; Wang, P.; Gu, M.; Hou, B.; Zhang, C.; Zheng, Y.; Sun, Y.; Jin, S.; Ye, N. Identification of PAL genes related to anthocyanin synthesis in tea plants and its correlation with anthocyanin content. Hortic. Plant J. 2021. [CrossRef]

75. Li, J.; An, Y.; Wang, L. Transcriptomic analysis of Ficus carica peels with a focus on the key genes for anthocyanin biosynthesis. Int J. Mol. Sci. 2020, 21, 1245. [CrossRef]

76. Sicilia, A.; Catara, V.; Scialò, E.; Piero, A.R. Lo Fungal infection induces anthocyanin biosynthesis and changes in dna methylation configuration of blood orange [Citrus sinensis L. (osbeck)]. Plants 2021, 10, 244. [CrossRef] [PubMed]

77. Zhang, S.; Sun, F.; Zhang, C.; Zhang, M.; Wang, W.; Zhang, C.; Xi, Y. Anthocyanin biosynthesis and a regulatory network of different-colored wheat grains revealed by multiomics analysis. J. Agric. Food Chem. 2022. [CrossRef]

78. Huang, J.; Gu, M.; Lai, Z.; Fan, B.; Shi, K.; Zhou, Y.H.; Yu, J.Q.; Chen, Z. Functional analysis of the Arabidopsis PAL gene family in plant growth, development, and response to environmental stress. Plant Physiol. 2010, 153, 1526-1538. [CrossRef]

79. Olsen, K.M.; Lea, U.S.; Slimestad, R.; Verheul, M.; Lillo, C. Differential expression of four Arabidopsis PAL genes; PAL1 and PAL2 have functional specialization in abiotic environmental-triggered flavonoid synthesis. J. Plant Physiol. 2008, 165, 1491-1499. [CrossRef] [PubMed]

80. Zhang, X.W.; Li, C.; Jiang, Q.T.; Wei, Y.; Yao, H.; Chen, H.; Wu, Q. Cloning and characterization of a cold inducible Pal promoter from Fagopyrum tataricum. Cent. Eur. J. Biol. 2014, 9, 290-297. [CrossRef]

81. Ariel, F.D.; Manavella, P.A.; Dezar, C.A.; Chan, R.L. The true story of the HD-Zip family. Trends Plant Sci. 2007, 12, 419-426. [CrossRef]

82. Chen, S.; Wang, S. GLABRA2, a common regulator for epidermal cell fate determination and anthocyanin biosynthesis in Arabidopsis. Int. J. Mol. Sci. 2019, 20, 4997. [CrossRef]

83. Rerie, W.G.; Feldmann, K.A.; Marks, M.D. The GLABRA2 gene encodes a homeo domain protein required for normal trichome development in Arabidopsis. Genes Dev. 1994, 8, 1388-1399. [CrossRef] [PubMed]

84. Di Cristina, M.; Sessa, G.; Dolan, L.; Linstead, P.; Baima, S.; Ruberti, I.; Morelli, G. The Arabidopsis Athb-10 (GLABRA2) is an HD-Zip protein required for regulation of root hair development. Plant J. 1996, 10, 393-402. [CrossRef] [PubMed]

85. Nakamura, M.; Katsumata, H.; Abe, M.; Yabe, N.; Komeda, Y.; Yamamoto, K.T.; Takahashi, T. Characterization of the class IV homeodomain-Leucine zipper gene family in Arabidopsis. Plant Physiol. 2006, 141, 1363-1375. [CrossRef] [PubMed]

86. Kubo, H.; Peeters, A.J.M.; Aarts, M.G.M.; Pereira, A.; Koornneef, M. ANTHOCYANINLESS2, a homeobox gene affecting anthocyanin distribution and root development in Arabidopsis. Plant Cell 1999, 11, 1217-1226. [CrossRef]

87. Kubo, H.; Hayashi, K. Characterization of root cells of anl2 mutant in Arabidopsis thaliana. Plant Sci. 2011, 180, 679-685. [CrossRef]

88. Braidot, E.; Zancani, M.; Petrussa, E.; Peresson, C.; Bertolini, A.; Patui, S.; Macrì, F.; Vianello, A. Transport and accumulation of flavonoids in grapevine (Vitis vinifera L.). Plant Signal. Behav. 2008, 3, 626-632. [CrossRef]

89. Kaur, S.; Sharma, N.; Kapoor, P.; Chunduri, V.; Pandey, A.K.; Garg, M. Spotlight on the overlapping routes and partners for anthocyanin transport in plants. Physiol. Plant 2021, 171, 868-881. [CrossRef] 
90. Mackon, E.; Jeazet Dongho Epse Mackon, G.C.; Ma, Y.; Haneef Kashif, M.; Ali, N.; Usman, B.; Liu, P. Recent insights into anthocyanin pigmentation, synthesis, trafficking, and regulatory mechanisms in Rice (Oryza sativa L.) Caryopsis. Biomolecules 2021, 11, 394. [CrossRef]

91. Bannoud, F.; Carvajal, S.; Ellison, S.; Senalik, D.; Gomez Talquenca, S.; Iorizzo, M.; Simon, P.W.; Cavagnaro, P.F. Genetic and transcription profile analysis of tissue-specific anthocyanin pigmentation in carrot root phloem. Genes 2021, 12, 1464. [CrossRef]

92. Jiang, T.; Zhang, M.; Wen, C.; Xie, X.; Tian, W.; Wen, S.; Lu, R.; Liu, L. Integrated metabolomic and transcriptomic analysis of the anthocyanin regulatory networks in Salvia miltiorrhiza Bge. flowers. BMC Plant Biol. 2020, 20, 349. [CrossRef]

93. Huang, B.; Rong, H.; Ye, Y.; Ni, Z.; Xu, M.; Zhang, W.; Xu, L. An Transcriptomic analysis of flower color variation in the ornamental crabapple (Malus spp.) half-sib family through Illumina and PacBio Sequel sequencing. Plant Physiol. Biochem. 2020, 149, 27-35. [CrossRef] [PubMed]

94. Roberts, W.R.; Roalson, E.H. Comparative transcriptome analyses of flower development in four species of Achimenes (Gesneriaceae). BMC Genom. 2017, 18, 240. [CrossRef] [PubMed]

95. Wang, L.; Pan, D.; Liang, M.; Abubakar, Y.S.; Li, J.; Lin, J.; Chen, S.; Chen, W. Regulation of anthocyanin biosynthesis in purple leaves of zijuan tea (Camellia sinensis var. kitamura). Int. J. Mol. Sci. 2017, 18, 833. [CrossRef]

96. Broadley, M.R.; White, P.J.; Hammond, J.P.; Zelko, I.; Lux, A. Zinc in plants. New Phytol. 2007, 173, 677-702. [CrossRef]

97. Luna-Vital, D.; Cortez, R.; Ongkowijoyo, P.; Gonzalez de Mejia, E. Protection of color and chemical degradation of anthocyanin from purple corn (Zea mays L.) by zinc ions and alginate through chemical interaction in a beverage model. Food Res. Int. 2018, 105, 169-177. [CrossRef] [PubMed]

98. Lee, S.; Kim, S.A.; Lee, J.; Guerinot, M.L.; An, G. Zinc deficiency-inducible OsZIP8 encodes a plasma membrane-localized zinc transporter in rice. Mol. Cells 2010, 29, 551-558. [CrossRef]

99. Sasaki, A.; Yamaji, N.; Mitani-Ueno, N.; Kashino, M.; Ma, J.F. A node-localized transporter OsZIP3 is responsible for the preferential distribution of $\mathrm{Zn}$ to developing tissues in rice. Plant J. 2015, 84, 374-384. [CrossRef]

100. Choi, J.S.; Yang, G.M. Development of new hybrid cultivar 'Senock' in Zoysiagrass. Kor. Turfgrass Sci. 2004, 18, $201-209$.

101. Emmons, R.; Rossi, F. Turfgrass Science and Mnagement, 5th ed.; Cengage Learning: Stamford, CT, USA, 2015 ; pp. 40-41.

102. Choi, J.-S.; Yang, G.-M. Development of new cultivar 'Millock' in zoysiagrass. Asian J. Turfgrass Sci. 2006, 20, 1-10.

103. Meng, X.; Yin, B.; Feng, H.L.; Zhang, S.; Liang, X.Q.; Meng, Q.W. Overexpression of R2R3-MYB gene leads to accumulation of anthocyanin and enhanced resistance to chilling and oxidative stress. Biol. Plant. 2014, 58, 121-130. [CrossRef]

104. Li, P.; Li, Y.J.; Zhang, F.J.; Zhang, G.Z.; Jiang, X.Y.; Yu, H.M.; Hou, B.K. The Arabidopsis UDP-glycosyltransferases UGT79B2 and UGT79B3, contribute to cold, salt and drought stress tolerance via modulating anthocyanin accumulation. Plant J. 2017, 89, 85-103. [CrossRef] [PubMed]

105. Jiang, L.; Tian, X.; Li, S.; Fu, Y.; Xu, J.; Wang, G. The AabHLH35 Transcription Factor Identified from Anthurium andraeanum is Involved in Cold and Drought Tolerance. Plants 2019, 8, 216. [CrossRef] [PubMed]

106. Karcher, D.E.; Richardson, M.D. Batch analysis of digital images to evaluate turfgrass characteristics. Crop Sci. 2005, 45, 1536-1539. [CrossRef]

107. Karcher, D.E.; Richardson, M.D. Quantifying turfgrass color using digital image analysis. Crop Sci. 2003, 43, 943-951. [CrossRef]

108. Kim, D.; Paggi, J.M.; Park, C.; Bennett, C.; Salzberg, S.L. Graph-based genome alignment and genotyping with HISAT2 and HISAT-genotype. Nat. Biotechnol. 2019, 37, 907-915. [CrossRef] [PubMed]

109. Edwards, K.D.; Fernandez-Pozo, N.; Drake-Stowe, K.; Humphry, M.; Evans, A.D.; Bombarely, A.; Allen, F.; Hurst, R.; White, B.; Kernodle, S.P.; et al. A reference genome for Nicotiana tabacum enables map-based cloning of homeologous loci implicated in nitrogen utilization efficiency. BMC Genomics 2017, 18, 1-14. [CrossRef]

110. Pertea, M.; Kim, D.; Pertea, G.M.; Leek, J.T.; Salzberg, S.L. Transcript-level expression analysis of RNA-seq experiments with HISAT, StringTie and Ballgown. Nat. Protoc. 2016, 11, 1650-1667. [CrossRef]

111. Love, M.I.; Huber, W.; Anders, S. Moderated estimation of fold change and dispersion for RNA-seq data with DESeq2. Genome Biol. 2014, 15, 1-21. [CrossRef]

112. Yu, G.; Wang, L.G.; Han, Y.; He, Q.Y. ClusterProfiler: An R package for comparing biological themes among gene clusters. Omi. A J. Integr. Biol. 2012, 16, 284-287. [CrossRef]

113. Ling, Q.L.; Feng, Y.X.; Lu, C.J.; Lin, Y.J.; Yu, X.Z. Genetic variation and gene expression of anthocyanin synthesis and transport related enzymes in Oryza sativa against thiocyanate. Plant Physiol. Biochem. 2021, 160, 18-26. [CrossRef] 